\title{
Solid Lipid Nanoparticles: An Approach to Improve Oral Drug Delivery
}

\author{
Néstor Mendoza-Muñoz ${ }^{1}$, Zaida Urbán-Morlán ${ }^{2}$, Gerardo Leyva-Gómez ${ }^{3}$, María de la Luz Zambrano-Zaragoza ${ }^{4}$, Elizabeth \\ Piñón-Segundo ${ }^{5}$ and David Quintanar-Guerrero ${ }^{6}$ \\ ${ }^{1}$ Laboratorio de Farmacia, Facultad de Ciencias Químicas, Universidad de Colima, Coquimatlán, Colima, México; \\ ${ }^{2}$ Laboratorio de Cromatografía, Facultad de Química, Universidad Autónoma de Yucatán, Colonia Inalámbrica, Mérida, \\ Yucatán, México; ${ }^{3}$ Departamento de Farmacia, Facultad de Química, Universidad Nacional Autónoma de México, Ciudad de \\ México, 04510, Mexico; ${ }^{4}$ Laboratorio de Procesos de Transformacion y Tecnologías Emergentes de Alimentos, FES- \\ Cuatitlan, Universidad Nacional Autonoma de Mexico, CP 54714, Cuautitlán Izcalli, Mexico ; ${ }^{5}$ Laboratorio de Sistemas \\ Farmacéuticos de Liberación Modificada, L13, Unidad de Investigación Multidisciplinaria, Facultad de Estudios Superiores \\ Cuautitlán, Universidad Nacional Autónoma de México, Edo de México, México; ${ }^{6}$ Laboratorio de Posgrado en Tecnología \\ Farmacéutica, Facultad de Estudios Superiores Cuautitlán, Universidad Nacional Autónoma de México, Edo. de México, \\ México
}

Corresponding author: David Quintanar-Guerrero, Laboratorio de Posgrado en Tecnología Farmacéutica, Facultad de Estudios Superiores Cuautitlán, Universidad Nacional Autónoma de México, CP. 54740, Av. 1 de mayo s/n, Cuautitlán Izcalli, Edo. de México, México ; email, quintana@unam.mx

Received, April 3, 2021; Revised, September 5, 2021; Accepted October 10, 2021, Published, October 12, 2021

\begin{abstract}
Nanoparticles have shown overall beneficial effects in drug administration. Specifically, solid lipid nanoparticles (SLN) have emerged as an alternative to polymer-based systems. However, the oral administration of SLN, the first choice for conventional medications, has not been addressed due to the taboo surrounding the complicated transit that this delivery route entails. This review focuses on the encapsulation of drugs into SLN as a strategy for improving oral administration. Examples of applications of SLN to enhance the absorption and bioavailability of poorly-soluble drugs and protect acid-labile active molecules are discussed. This work also emphasizes the importance of developing SLN-based systems to treat health issues such as neurological diseases and cancer, and combat antibiotic resistance, three significant and increasingly common current public health problems. The review sections clarify how SLN can improve bioavailability, target therapeutic agents, and reduce side effects.
\end{abstract}

\section{INTRODUCTION}

Over the years, lipids have been used as excipients in numerous pharmaceutical formulations, such as suppositories, ointments, and emulsions, and more recently as raw materials for nanosized drug carriers. The emulsions are versatile systems that can deliver oil-soluble agents over various routes. They consist of dispersions of a liquid lipid material into an aqueous phase (in the case of $\mathrm{O} / \mathrm{W}$ emulsions), but drawbacks of these systems include rapid drug release, instability processes, and oxidation. In the 1990s, a novel drug carrier type was developeded to resolve the issues associated with conventional emulsions, namely, solid lipid nanoparticles (SLN). These are dispersions of submicron-sized particles composed of a solid lipid matrix that is solid at body and room temperature, stabilized by a surfactant $(1,2)$. The nano-size range $(100-1000 \mathrm{~nm})$ of SLN facilitates their characteristic properties compared to larger particles. Also, tunable physiochemical properties are possible due to the large surfacevolume ratio resulting from the nano-size (3).

Since then, several studies have revealed and confirmed the advantages of SLN, especially low toxicity, efficient drug targeting, controlled drug release, high drug loading (especially for lipophilic drugs), protection from degradation, versatility since both lipophilic and hydrophilic drugs can be incorporated - and occlusive properties $(2,4,5)$. One of the main applications of SLN has consisted in enhancing the absorption and bioavailability of poorly-soluble drugs (6-9). However, many pharmaceutical dosages today still present intra- and interpatient variability and low bioavailability, which means low efficiency. This is particularly true for antibiotics, brain treatments, and anticancer drugs, all 
of which can benefit from the significant advantages of using SLN as drug carriers.

Acid labile or poorly-soluble antibiotics make it necessary to introduce the active agent into the body through a pathway distinct from the oral route; intravenously, for example. However, economic pressures to provide optimal care at lower cost and other considerations for parenteral products are fomenting the development of novel strategies to increase the effectiveness of the oral route. Neurological diseases are a significant, growing public health problem, but the efficacy of treatments based on existing drugs is relatively low, and many therapies have significant side effects or require highly invasive procedures. According to the World Health Organization (WHO), cancer is a leading cause of morbidity and mortality worldwide. In 2012 alone, 14 million new cases were diagnosed, and this number is expected to increase by about $70 \%$ over the next two decades (10). Cancer represents a group of diseases characterized by abnormal, uncontrolled cell growth that can affect any part of the body. While treatment efficiency has improved, anti-cancer drugs lack tumor-tissue selectivity, often producing severe side effects. SLN offers an alternative for improving the oral bioavailability of medicines for neurological and cancer patients.

This article analyzes information regarding the general advantages of SLN, such as increasing the bioavailability of poorly-soluble drugs and protecting it against $\mathrm{pH}$ degradation in the gastrointestinal tract. In addition, essential applications of SLN in high-incidence diseases are identified with descriptions of how these nanocarriers can enhance treatment efficacy. This exhaustive review thus responds to the pressing need to address such key issues in modern medicine as neurological diseases, cancer, and antibiotic therapy.

\section{ENHANCING THE ORAL BIOAVAILABILITY OF POORLY-SOLUBLE DRUGS USING SLN}

SLN have been developed in recent decades as an important option for the delivery of many drugs because of the significant advantages they offer compared to earlier systems: first, improving in vitro and in vivo stability; second, reducing harmful side effects; and third, enhancing delivery to specific tissues or cells by combining with other molecules. Two issues that remain to be resolved in the use of
SLN are achieving compatibility with the physiological environment and preventing interaction with the immune system that can lead to unspecific uptake. The drug route to reach the action site is challenging because it has to cross various physiological barriers. Poorly-soluble drugs administered orally must pass through the stomach to reach the lumen of the intestine, where they have to traverse both the mucus layer that coats the epithelium and the epithelium itself (11).

Several biopharmaceutical agents, including peptides and proteins, have low solubility, so they must be administered by injection or infusion. In this regard, the oral route has significant limitations because the drugs may be digested in the stomach or intestines, rendering them ineffective. SLN may constitute an option for the oral administration of poorly-soluble molecules by protecting the active ingredient, increase its stability, and, with adequate surface modification, conceal it from the immune system or target them to the desired tissue or cell, but this requires a thorough understanding of crucial features of the gastrointestinal tract. The villi that cover the intestinal epithelium increase the surface area available for absorption, calculated as approximately $400 \mathrm{~m}^{2}$. These villi are covered by absorptive enterocyte cells and mucus-secreting goblet cells that form lymphoid nodules with the follicle-associated epithelium, the Peyer's patches. These, in turn, are coated with $\mathrm{M}$ cells whose role is to sample antigens. These cells provide less protection to the mucus and have high transcytotic activity, but their population is relatively low $(<1 \%)$ and is not considered a major route for absorption. Finally, but also important, the lumen of the small intestine contains bile salts, pancreatic enzymes, and a thick mucus layer, all of which have a significant impact on drug bioavailability because permeability through the mucus can be low, or degradation may occur before absorption (12,13). So, what mechanisms exist to enhance the oral bioavailability of drugs when administered in an SLN formulation?

A first mechanism is the adhesion capacity of these lipid nanoparticles $(14,15)$, which allows close contact with the gut wall and releases the drug at the intended absorption site. Lipids are also recognized as absorption-promoting agents for various molecules (16-18). A third feature is that SLN formulations can take a distinct route since they are composed of lipids that are very similar to physiological ones and so can be metabolized by 
pancreatic lipases that release drug and degradation products (diglycerides and fatty acids). Diglycerides can form mixed micelles with bile salts containing the solubilized drug such that the body absorbs the lipids and drugs at the same time. This means that SLN can act as a kind of Trojan horse $(19,20)$. On this route, both the lipids and the drug are easily absorbed via chylomicron formation, especially into the lymphatic system. This is advantageous because it avoids the first-pass effect (21). Studies have further demonstrated the importance of SLN uptake into enterocytes by the clathrin- and caveolaemediated endocytosis pathway because this allows drugs to reach systemic circulation via portal circulation and the intestinal lymphatic pathway $(14,21)$. Finally, the mechanism involved in the phagocytosis of Peyer's patches and other mucosaassociated with lymphoid tissues via $\mathrm{M}$ cells has been proposed to explain the enhanced oral bioavailability of amphotericin B polymer lipid hybrid nanoparticles structured with lecithin and gelatin (22).

Figure 1 illustrates the possible mechanisms of intestinal absorption of SLN, while the following paragraphs discuss some exciting approaches that help drugs with low solubility or, in general, poor biopharmaceutical properties, and orally administered, to overcoming the physiological barriers.

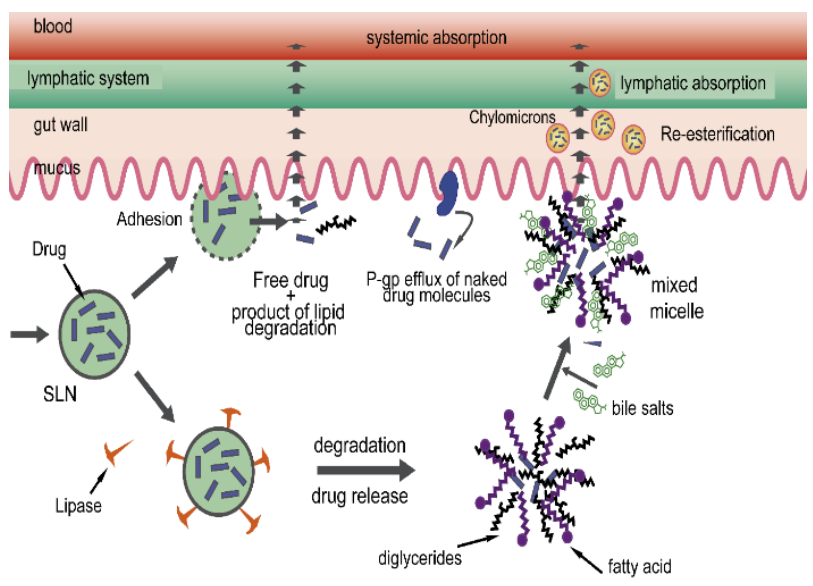

monsmonnmy

Figure 1. Routes by which solid lipid nanoparticles can deliver a drug across enterocytes.

A well-known example of bioavailability enhancement involves the drug cyclosporine A. Müller et al. (23) compared the performance of cyclosporine A-loaded SLN vs. nanocrystals formed with this drug, both of which were administered orally to pigs in order to obtain plasma profiles. The SLN presented low variations similar to the commercial reference presentation (Sandimmun Neoral/Optoral ${ }^{\circledR}$ ) but no maximum initial blood peak, while the nanocrystals had variable, low blood concentrations. A comparison of the area under the curves of the formulations proved that SLN blood concentrations were below $1000 \mathrm{ng} / \mathrm{mL}$, avoiding possible side effects. This study demonstrated that SLN could improve the oral bioavailability of cyclosporine and avoid the plasma peak of cyclosporine that occurs with the commercial Sandimmun ${ }^{\circledR}$ formulation.

The cholesterol-lowering but poorly watersoluble drug simvastatin was encapsulated in SLN to improve its oral bioavailability because it undergoes extensive metabolism in the gastrointestinal tract and liver by the cytochrome $3 \mathrm{~A}$ system. The authors designed two types of SLN with distinct components. Both formulations enhanced oral bioavailability (approximately 3- or 2-fold) compared to the free drug (24). In a related research, Rizvi et al. (25) developed simvastatin-loaded SLN to study their anti-hyperlipidemic effect by measuring cholesterol levels in rats induced to hyperlipidemia. The SLNloaded formulation reduced serum lipids and total cholesterol by $\sim 3.9$ and $~ 1.5$-times, in comparison with the control and simvastatin dispersions. Moreover, another anti-hyperlipidemic agent, rosuvastatin calcium, was encapsulated into SLN and the researchers confirmed that these carriers significantly improved such pharmacokinetic parameters as $\mathrm{C}_{\max }$ and $\mathrm{AUC}_{\text {last }}$ compared to the pure drug (26).

A comparison of the pharmacokinetics and relative bioavailability of SLN containing puerarin $v s$. a suspension of this drug revealed a greater than 3 -fold improvement in oral bioavailability when administered into nanocarriers, with high tissue concentrations in the target organs (heart, brain). The authors concluded that the SLN enhanced the drug's oral absorption and, therefore, represents a promising delivery system for treating cardio-cerebrovascular diseases (27). Furthermore, it is well known that nanoparticles can deliver and target active molecules in the intended site; for these diseases, an interesting approach to explore is the nano-coating of medical implants expecting higher bioavailability (28).

In other work, SLN loaded with curcumin -an agent used to treat neurodegenerative disorders and 
cancer- were tested for their potential to enhance oral bioavailability (29). Results indicated a marked bioavailability increase at all four doses applied; that is, 39 times at $50 \mathrm{mg} / \mathrm{kg} ; 12.5$ times at $25 \mathrm{mg} / \mathrm{kg} ; 32$ times at $12.5 \mathrm{mg} / \mathrm{kg}$; and 155 times at $1 \mathrm{mg} / \mathrm{kg}$, all administered orally and compared to the bioavailability achieved with curcumin in solution. These results evidenced the usefulness of SLN to promote long circulation times and to reduce elimination from the systemic circulation, thereby improving bioavailability. Abuasal et al. (30) proposed employing SLN as a carrier of tocotrienol, an anticancer agent, to enhance its intestinal permeability and, as a result, its oral bioavailability. This agent is lipophilic and previous studies had shown its low intestinal permeability. In situ permeability and in vivo relative oral bioavailability studies demonstrated 10-fold and 3-fold increases, respectively, when administered in SLN.

Some antihypertensive drugs have also enhanced their oral bioavailability after encapsulation in SLN. A pharmacokinetic study that compared the performance of nimodipine-loaded SLN vs. a nimodipine solution revealed that the nanocarriers presented a 2.08 -fold increase in relative oral bioavailability (31). Another experiment improved the solubilization of candesartan cilexetil in the gastrointestinal environment by formulating SLN which were bioadhesive to the intestinal membrane. SLN enhanced the candesartan oral bioavailability compared to a free candesartan suspension (32). He et al. (27) recently encapsulated the antihypertensive agent felodipine into SLN because this poorly water-soluble and extensively metabolized molecule (by the liver) has low bioavailability. After oral administration of SLN and the free drug in beagles, the $\mathrm{AUC}_{(0-\mathrm{t})}$ value improved 3.17-fold with the carriers. In the case of the antiarrhythmic agent dronedarone hydrochloride, the SLN formulation showed a 2.68 -fold increase of bioavailability over the value found for the drug in suspension (33).

In a comparative study of the pharmacokinetic performance of lopinavir-loaded SLN $v s$. a marketed lopinavir/ritonavir co-formulation, the authors observed a 5 -fold increase in the oral bioavailability of the lopinavir incorporated into nanoparticles compared to the free form. In addition, the SLN formulation protected the drug from metabolic degradation, leading the authors to conclude that it enhanced performance and was preferable to the commercial lopinavir/ritonavir co-formulation (21).

In 2014, Dwivedi et al. (34) encapsulated arteether into SLN. Arteether is an artemisinin derivative used to treat multiple-drug-resistant malaria. Their pharmacokinetic study showed that both adsorption and relative bioavailability improved significantly compared to arteether in suspension or administered in groundnut oil. In the case of niclosamide, which has low water solubility but provides anti-helminthic, anti-proliferative, and antitumor activity, SLN were prepared in a trial designed to improve its performance. This pharmacokinetic study showed promising results because the peak plasma concentration of the SLN was 2.15-fold higher than that obtained for the commercial product (35).

In another approach, the poorly water-soluble and water-permeable drug tripterine was encapsulated in lipid nanospheres to enhance oral bioavailability. The authors found that nanoencapsulation improved intestinal permeability and post-enterocyte lymphatic transport were the main enhanced factors during oral absorption. The drug's relative oral bioavailability increased significantly compared to a suspension (36).

Insulin is another drug that has been encapsulated into SLN. In 2015, a study evaluated these nanocarriers in terms of production parameters, characterization, in vitro release, permeation, stability, bioavailability, and pharmacological performance for oral delivery of insulin. Results showed a 5-fold increase in relative bioavailability compared to an insulin solution $(8.26 \%$ vs. $1.7 \%)$ (37).

Gonçalves and cols. (38) prepared glibenclamide-loaded SLN to determine if they improved this drug's oral bioavailability, which has low water solubility. They added lecithin to an SLN core and performed in vivo studies that demonstrated a significantly stronger hypoglycemic effect compared to that exerted by the drug alone. Those authors concluded that SLN definitively improved the oral bioavailability of glibenclamide.

An exciting system proposed by Cirri et al. (39) incorporated a hydrochlorothiazide-cyclodextrin complex into SLN. Their work revealed improved bioavailability and sustained release. In general, these SLN formulations performed better in terms of drug release rate than a suspension and free drugloaded SLN but incorporating a co-ground drug- 
cyclodextrin complex exhibited even better results than the physical mixtures.

Dudhipala and Janga (40) prepared SLN containing zaleplon, a low-soluble hypnotic drug used to treat insomnia and convulsions. They utilized a Box-Behnken design to optimize and evaluate the in vitro and in vivo performance of those SLN and determine the best experimental conditions for improving bioavailability. Their study demonstrated enhanced oral bioavailability of the zaleplon-loaded SLN compared to the control zaleplon suspension.

In another study, Aman et al. (41) developed chitosan-based apocynin-loaded SLN to counteract the rapid elimination and low bioavailability characteristic of this phytochemical. They reported both oral and intravenous bioavailability enhancement in rats with the optimized SLN formula compared to an apocynin solution. This represents a promising approach to treating neurodegenerative diseases. Resveratrol, a natural polyphenol with low and variable bioavailability but essential pharmacological activity, has also been formulated in SLN. The results of a pharmacokinetic study of this compound showed a significant 8-fold improvement in oral bioavailability compared to a suspension (42). Similarly, Kang et al. (43) prepared SLN with magnesium lithospermate B, a poorly water-soluble polyphenol with multiple pharmacological actions (anti-oxidation, anti-apoptosis, among others). The authors found a significant enhancement of the $C_{\max }$ and AUC of the magnesium lithospermate in SLN compared to a solution.

\section{PROTECTIVE EFFECT OF SLN AGAINST HYDROLYSIS OF DRUGS ADMINISTERED ORALLY}

SLN constitutes an especially attractive pharmaceutical nanoplatforms for oral drug delivery because they offer several advantages when administered via this route, including, above all, better biodegradability and well-tolerated composition due to the incorporation of natural and synthetic lipids $(44,45)$. Moreover, SLN preparations are virtually tasteless, can encapsulate large doses of drugs, and are integrated into solid or liquid dosage forms. They can also adhere to the gut wall to increase the bioavailability of drugs, increase the solubility of poorly-soluble drugs, and protect active ingredients from degradation in the stomach's acidic environment. Under fasting conditions, the $\mathrm{pH}$ in the stomach may range from 2-6, while after a meal, this level may drop below 2 . Some drugs are chemically unstable at normal gastric acid $\mathrm{pH}$; that is, conditions under which molecules susceptible to hydrolysis reactions are easily degraded into their sub-products or metabolites. Other drugs may require protection to reach a specific intestine area at sufficiently high concentrations, for example, in anthelmintic therapy or colonic delivery.

Encapsulating drugs have emerged as a practical means of protecting drugs from degradation. In the case of SLN, the drug is either incorporated into a lipid matrix where it disperses molecularly (solid solution model) or is formed into a drug-enriched nucleus covered by a lipid shell (core-shell model) (46). The active ingredient of a drug incorporated into a shell will be highly susceptible to degradation, but protection from degradation can be achieved if the molecule remains inside the nanoparticle's lipid matrix. If the nanoparticle matrix degrades in the gastric fluids, thus the drug will dissolve as well. The degradation of drugs due mainly to hydrolysis in the gastrointestinal tract can be controlled by encapsulating them in SLN (15).

An example is the antibiotic rifampicin, a drug prescribed in cases of pulmonary tuberculosis. Rifampicin is known to decompose rapidly in the presence of isoniazid under acidic conditions, like those in the stomach. Singh et al. (47) demonstrated the protective effect of SLN in reducing the hydrolysis of rifampicin in acidic $\mathrm{pH}$ and the presence of isoniazid. Their solution of rifampicin decomposed at a rate of $26.5 \%$ with an increase to $48.8 \%$ in the presence of free isoniazid. When the rifampicin was encapsulated in SLN, in contrast, degradation decreased to around $19.5 \%$ in the presence of free isoniazid and just $12 \%$ in the presence of isoniazid also incorporated into SLN. The authors concluded that the SLN with rifampicin impeded degradation nearly three-fold compared to free rifampicin.

Ensuring adequate protection of the drug depends significantly on the stability of the SLN matrix. This means that suitable components must be chosen during the formulation process to maximize stability. An especially important aspect is that the lipid must resist the acid environment and enzymatic digestion in the stomach, so it must be selected carefully. Several lipids have been employed in formulating SLN (48), including glycerides like 
glycerol monostearate, glycerol trilaurate, glycerol behenate, glycerol tripalmitate, glycerol myristate, glycerol tricaprate, glycerol tristearate, and hydrogenated coco-glyceride; fatty acids such as stearic acid, behenic acid, decanoic acid, and palmitic acid; fatty esters like cetyl palmitate; and carnauba wax and beeswax. The degradation of the lipid matrix occurs mainly through the action of enzymes such as lipases and, to a lesser degree, hydrolytic processes (49-51). The rate of hydrolysis in SLN is fastest for triglycerides, followed by di- and monoglycerides (52).

To prolong stability, SLN can include cores or compounds that reduce enzymatic activity. Olbrich and cols. (50), for example, reported that a combination of specific long-chain triglycerides with a non-ionic emulsifier reduced lipase-mediated degradation of SLN after oral administration, while sterically-hindering surfactants such as poloxamer 407 or poloxamine 908 successfully delayed the degradation of SLN. Luo et al. (53) evaluated the effect of a chitosan coating on SLN to improve stability, mucoadhesion, and cellular uptake. Their results showed that chitosan improved SLN stability under simulated gastric conditions by forming a thick layer around the lipid core. According to $\mathrm{Hu}$ and cols. (54), SLN may penetrate deeply into the gastric mucus and be retained there with concurrent transiting downstream upon periodic refreshing of the gastric mucus. This discovery led to the inference that SLN can resist degradation in the stomach for enough time to protect active ingredients under normal conditions (lipase activity) and that the protection time can be extended using lipaseinhibition. However, the transit of nanoscale particles can be modified by the food ingested so that the gastric emptying rate may play a significant role in the overall retention of SLN and the degradation of actives incorporated in SLN.

The number of peptides and proteins used for therapeutic purposes has grown significantly in recent decades, but finding effective delivery systems has limited their application. Though oral delivery is preferred, most of these substances are still delivered intravenously or subcutaneously due to rapid degradation and limited absorption in the gastrointestinal tract. For this reason, SLN have been tested as potential carriers for the oral administration of peptides. The lipid core of the SLN are designed to protect against hydrolysis and control the release of the biomolecules. Insulin is one of the most widely-studied peptides formulated into SLN for oral delivery as a non-invasive therapy for diabetes mellitus because it is subject to rapid enzymatic degradation in the stomach, inactivation, and digestion by enzymes in the intestinal lumen, in addition to its low permeability across the intestinal epithelium. SLN formulations may be able to overcome these limitations. Ansari et al. (37) developed insulin-loaded SLN using glycerol trimyristate with high peptide entrapment (57\%). Their formulation increased bioavailability. Zhang et al. (55) designed and characterized SLN modified with stearic acid-octa-arginine (SA-R8) and performed enzymatic stability studies with pepsin (under acidic conditions) and trypsin (under alkaline conditions) to evaluate the protective effect against gastrointestinal degradation of insulin-loaded SLN compared to a free insulin solution. They found that approximately 45.6 and $54.7 \%$ of the insulin remained after $1 \mathrm{~h}$ of incubation for unmodified SLN and SLN modified with SA-R8, respectively. Studies in simulated intestinal fluid with the presence of trypsin showed that free insulin degrades more slowly in trypsin than pepsin because $6.4 \%$ of the insulin remained after $4 \mathrm{~h}$. In the same study, about $11.6 \%$ of the insulin was recovered after $4 \mathrm{~h}$ of incubation of the unmodified SLN, and $25.7 \%$ in SLN modified with SA-R8 after $4 \mathrm{~h}$ of incubation with trypsin. These results suggest that the lipid matrix of the SLN was advantageous in protecting insulin from enzymatic degradation.

\section{ORALLY-ADMINISTERED SOLID LIPID NANOPARTICLES (SLN) FOR BRAIN DRUG DELIVERY}

The oral administration route for drug delivery is convenient because of its ease of application (56). Current research on new formulations for transporting drugs to the brain focuses on highpotency drugs requiring only low doses because a small fraction of the carrier/drug in the brain suffices to produce the desired therapeutic effect. However, the results of studies centered on this administration route remain modest due to the challenge of finding a carrier capable of maintaining its integrity and direction over the long distance that the drug needs to travel to reach the target site in the brain (57). The longer the circulation path of a carrier system, the longer the retention time and, therefore, the greater the drug loss (see Figure 2). Despite this limitation, 
some successful cases of drug transport to the brain using nanoparticles via oral administration have been reported. Using SLN for brain targeting via this route is vital as an alternative carrier to polymeric nanoparticles, as is our understanding of the assimilation of fatty components and digestion and biodegradation processes. In a notable study, Kakkar et al. (58) formulated SLN based on Compritol ${ }^{\circledR} 888$ ATO and Tween ${ }^{\circledR} 80$ to encapsulate curcumin by a microemulsion method to improve the drug's therapeutic effect and possible applications in Alzheimer's disease, depression, and stroke, and its apoptotic effect on cancer cell lines, all concerning the brain. One-hour post oral administration of the curcumin-SLN in rats, the AUC value was 8.135 times higher than that of curcumin, demonstrated by radiolabeling with ${ }^{99 \mathrm{~m}} \mathrm{Tc}$, complemented by the presence of fluorescent yellow particles in the brain detected by fluorescence microscopy. That study tested the prolonged circulation of the carrier and its ability to cross the gut wall and blood-brain barrier (BBB).

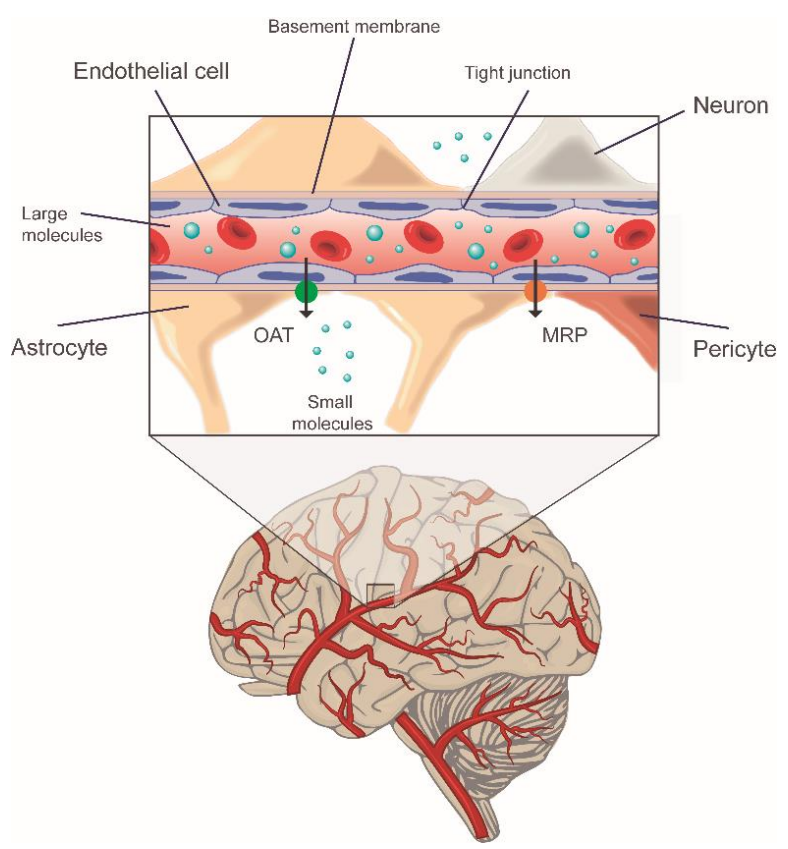

Figure 2. The blood-brain barrier, one of the main challenges that SLN face in drug transport to the brain.

Using a similar experimental approach, Ramalingam and Ko (59) employed the high-shear homogenization with ultra-sonication technique to prepare N-trimethyl chitosan surface-modified SLN with palmitic acid carrying curcumin. Their formulation increased oral bioavailability by almost
26 times for $\mathrm{AUC}_{0-8 \mathrm{~h}}$, and 5 times for $\mathrm{C}_{\max }$, with distribution in the brain, possibly due to the interaction of the nanoparticles positive charge with the negative charges of the cell membranes. This formulation improved oral absorption while decreasing enzymatic degradation and rapid elimination. Also, Zhou et al. (60) incorporated venlafaxine into SLN (VLX-SLN). VLX is an antidepressant of the norepinephrine reuptake inhibitor class utilized as the first choice in treating major depressive and general anxiety disorders. It is pumped out of the brain by P-glycoprotein (P-gp), so a VLX-SLN formulation was tested to overcome this effect. The VLX-SLN were attached to poloxamer 188 as a stabilizer, using the microemulsion technique. The authors recorded increases of 1.5 and 1.45 times for $\mathrm{AUC}_{0-10 \mathrm{~h}}$ and $\mathrm{C}_{\max }$ when VLX.-SLN was incorporated, corresponding to increased plasma parameters. In this respect, SLN formulations can be non-specific inhibitors of P-gp with low pharmacological activity and reduced side effects.

Moreover, Leyva-Gómez et al. (61) formulated clonazepam into SLN (CLZ-SLN) of Compritol ${ }^{\circledR} 888$ ATO by the emulsification-diffusion method. In this case, oral administration prevented pentylenetetrazole-induced seizures in mice. This activity was corroborated by observations of behavioral aspects and electroencephalogram recordings in rats, where the frequency, duration, and spread of spike-waves all decreased. While their study did not include a pharmacokinetic analysis, the hCMEC/D3 cell line was used in BBB permeability studies, and an increase in permeation through the cells was recorded when CLZ-SLN was applied. The practical result of the increase of the brain carrier was an increase in the therapeutic effect in the in vivo model that reflects a high concentration of the drug in the brain, though the nanoparticle matrix material may produce a therapeutic effect, as some studies have demonstrated (61). The latter situation may be exempt from a toxicity classification of NP when beneficial effects are recorded for the biological organism involved. Though still not widely studied, this approach could lead to new therapeutic applications of these materials that could increase the biocompatibility of nanoparticle-drug conjugates by decreasing the amount of drug administered.

Recent advances demonstrated that lipids have various functions in the central nervous system (CNS) as both ligands and substrates for proteins. Lipids alter the geometric properties of membranes, 
control protein traffic, and provide messenger molecules that mediate communication between cells (62). The phospholipid bilayer and associated lipids provide a permeability barrier and a structured environment that is essential for membrane-bound proteins to perform their proper role (63). Lipidomic analyses provide a suitable tool for elucidating the specific roles of lipid intermediates in cell signaling, so more in-depth knowledge of the complexity of lipid signaling will increase our understanding of the role of lipid metabolism in various CNS disorders and open new opportunities for the development of drugs and therapies designed to treat neurological diseases (64). Lipid carriers such as SLN prepared with Compritol $^{\circledR} 888$ ATO revealed that the proportion of lipid content plays an essential role in modulating excitability in the brain. The term "excitability" is commonly used in the literature, especially in medicine and biology, to characterize the state or activity of such nerve centers as the brain and spinal cord.

Both standard and abnormal behavior patterns require a certain degree of synchronization in the firing of a population of neurons that are influenced by synaptic and non-synaptic interconnections (65). Studies have shown that the ketogenic diet is a successful therapy for controlling seizures in children (66) and adults (67). Though the action mechanisms through which this therapy induces anticonvulsant effects are not entirely clear, it has been suggested that fatty acids may be used to synthesize the three ketone bodies ( $\beta$ hydroxybutyrate, acetoacetate, acetone), so they can enter the brain and replace glucose by an alternate source of energy. In the developing brain, in contrast, these elements constitute essential building blocks for cell membranes and lipids (68).

In another aspect, chronic ketosis is thought to modify the tricarboxylic acid cycle, which would increase glutamate and, subsequently, GABA synthesis in the brain (69). The ketogenic diet generates adaptive changes in the brain's energy metabolism that increase energy reserves. Ketone bodies are a more efficient fuel than glucose because they induce an increase in the number of mitochondria that could help neurons remain stable under the increased energy demands occasioned by a seizure, thus potentially providing neuroprotection. It has been hypothesized that some of these action mechanisms may be involved in the synergistic anticonvulsant response observed with CLZ-SLN, though further research is needed to corroborate this (61).

To date, the use of p.o. administration for pharmacological therapies conducted to the brain has represented a significant challenge, but several possible solutions for therapeutic alternatives are currently under development (Figure 3 ). In this regard, advances in various areas in medical science are offering new perspectives and new challenges. For example, pondering the design of transporters for gene therapy at the cerebral level by p.o. administration is currently an important challenge in the field of pharmaceutical technology.

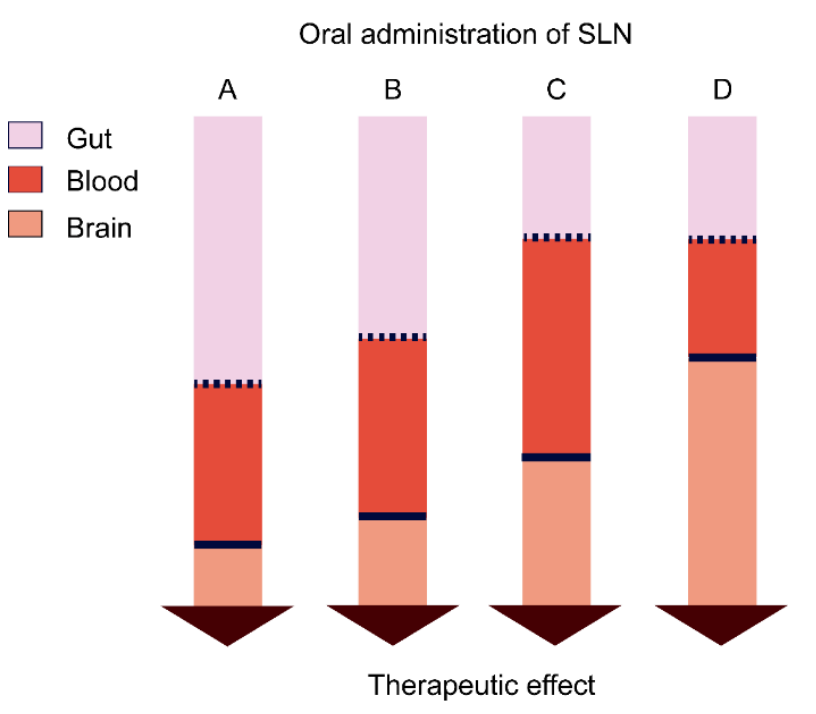

Figure 3. Oral (A, B, C) vs. intravenous (i.v.) (D) administration of SLN and the fraction of the formulation that reaches the brain. Uncoated SLN (A); SLN coated with hydrophilic polymers like polyethylene glycol (PEG) (B); and SLN coated with both hydrophilic polymers and a specific ligand at the level of the BBB. As depicted in the different shades, the percentage of SLN varied according to the function of the nanoparticle surface to highlight the potentiality of surface phenomena. Modified from Kaur et al.

This may involve internalizing the transporter in the cytoplasm at the neural level and, in some cases, even at the nuclear level (59). For these purposes, the use of Tween 80 and poloxamer 188 may help SLN cross the BBB (70). Molecules like PSC833 (71), GF120918 (72), and chlorpromazine (73) can be incorporated onto the surface to inhibit efflux pumps. For cell penetration, the use of transporters like penetratin, TAT and RVG derivatives, neurotensin, and polyarginine is currently extensive (74), while the classic use of 
polyethyleneimine is highly-effective for escape from the endosome, (75). Regarding nuclear internalization, karyophilic peptides have been reported to function with high efficiency (76). In this respect, it is crucial to consider a balance between the degree of vectorization required at the action site and along the entire transport route, as demonstrated by the effect of corona formation on the surface of nanoparticles This phenomenon refers to the adsorption of proteins into nanoparticles from the biological environment, described mainly about the bloodstream. However, this cover has been controlled by pegylation techniques and similar modifications that increase surface hydrophilicity. Thus, if the anchoring of specific ligands is performed -for example, for gene therapy following p.o. administration-it could be that the corona would inhibit potential vectorization. To date, however, this prediction has only been evidenced by in vivo tests.

Another aspect to consider in developing novel SLN-based systems for drug release in the brain after p.o. administration is the toxicological status of the SLN and their degradation products. Two key features of using SLN that contain polymeric nanoparticles are biocompatibility and biodegradation. However, it is necessary to conduct broad studies on toxicity in different neural lines and elucidate, insofar as possible, internalization mechanisms at the level of the brain. Therefore, new pharmacokinetic and pharmacodynamic studies of the drug and carrier are necessary, but this will require novel methods for tracking nanoparticles by in vivo systems.

\section{IMPROVING ORAL BIOAVAILABILITY OF ANTICANCER DRUGS BY SLN}

The physicochemical properties of many anticancer agents and the physiological features of the gastrointestinal tract $(\mathrm{pH}$ variations, pre-systemic metabolism) are huge challenges for oral delivery since only a small fraction of the dose administered reaches systemic circulation to exert its therapeutic effect. This may be due to poor intestinal permeability, low water solubility, pre-systemic metabolism, or high P-gp efflux levels. The latter has a significant impact on the development of drug resistance in tumor cells because the amount of drug needed to achieve the therapeutic effect can be relatively high and lead to multidrug resistance.
Designing new formulations of existing drugs for administration through the parenteral route that have reasonable manufacturing costs and a narrow therapeutic window are two restrictions on oral administration. This shows the need for more effective strategies that can overcome these limitations. Nanotechnology represents a promising field of research for developing novel drug delivery systems with potential advantages; for example, polymeric nanoparticles, micelles, liposomes, selfemulsifying drug delivery systems, nanocrystals, lipid-drug conjugates, and SLN, among others. Various systems exist, and each one offers crucial technological and biopharmaceutical advantages. Therapeutic efficacy depends on delivering the drug to the target site at a precise time and in sufficient quantity to achieve the desired therapeutic effect (77). Some colloidal drug carriers can improve drugs' therapeutic efficacy or safety profile in cancer therapy, and SLN, for example, is thought to fulfill these requirements. They have been proposed as carriers for numerous drugs due to certain advantages: low toxicity, high biocompatibility, increased bioavailability, and enhanced drug targeting $(78,79)$. Because of these benefits, SLN have been widely studied as transporters of drugs for cancer treatment, so their current uses and prospects are discussed in detail in the following section. It is important to highlight some essential features that must have the carrier to be targeted in cancerous tissue such as its correct size (should be 1-100 nm), adequate stability to avoid drug loss, and enough safety to prevent the damage of healthy tissues (80).

Several classes of anticancer drugs have been formulated in SLN; examples include camptothecins, taxanes, anthracyclines, etoposide, fluorodeoxyuridine, retinoic acid, and such compounds as small interfering RNA (siRNA) and resveratrol $(42,78,81)$. A disadvantage of all these proposed formulations is that, to the best of our knowledge, no clinical studies have yet been conducted to support their use, though in vitro and in vivo work with animals show promising results that include enhanced intracellular delivery and bioavailability of the encapsulated agents $(29,82)$. In this regard, one characteristic to take advantage of, is the high permeability of blood vessels in cancer tissues, because the size of gaps among them is larger than $100 \mathrm{~nm}$, therefore nanoparticles can pass the damaged tissue and remain there, this is the Enhanced Permeability and Retention effect (80). 
The main strategies developed to overcome the challenges of SLN-based anticancer treatments can be summarized as follows: encapsulating watersoluble anticancer compounds, controlling drug release rates and the extent of drug release, and preventing systemic clearance of the SLN by the reticuloendothelial system (RES). Examples of these and other approaches utilized to enhance oral bioavailability and other key aspects are presented below. Figure 4 shows the main SLN anticancer approaches developed to date.

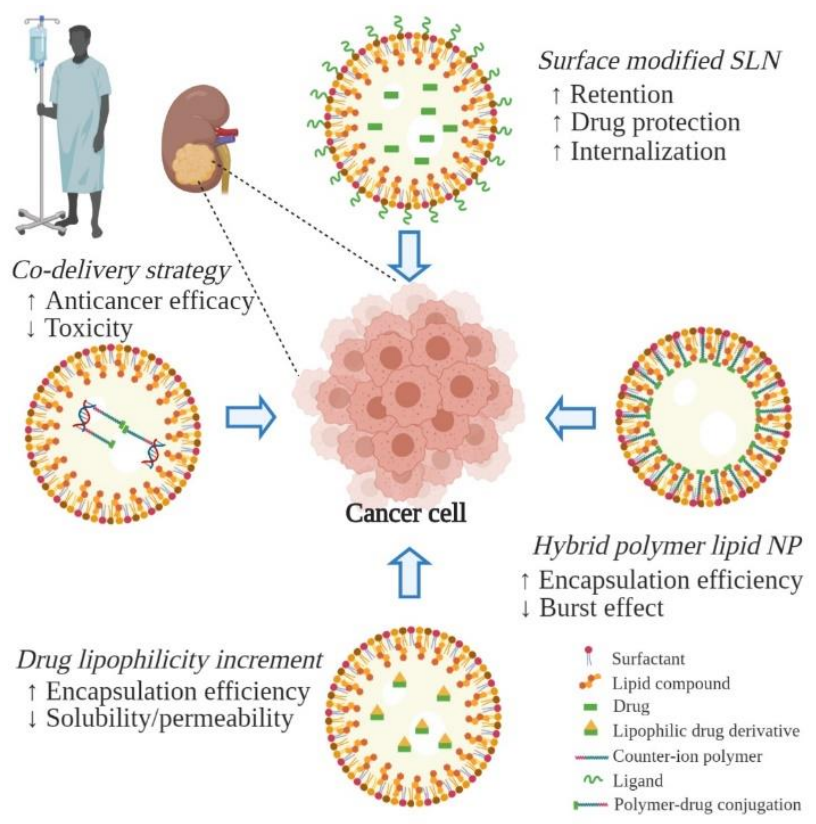

Figure 4. SLN anticancer approaches developed: a) surface modified SLN; b) hybrid polymer lipid nanoparticles; c) drug lipophilicity increment; d) codelivery strategy (figure created with BioRender.com).

Some frequently used anticancer drugs are salts solubilized in water-based vehicles $(0.9 \%$ saline $)$. The preparation of SLN to encapsulate these compounds may present some difficulties because they may be partitioned into the aqueous phase during dispersion, resulting in low drug-loading and encapsulation efficiency. However, the amount of many anticancer agents required to achieve the desired anticancer effect is only a few milligrams, so SLN could be an ideal choice for administering larger quantities of water-soluble compounds. To date, two approaches have been developed to encapsulate ionic salts. The first is based on ion-pair formation by adding an appropriate counter-ion $(83,84)$. The second consists in preparing lipid drug conjugate
(LDC) nanoparticles (85). Both approaches are designed to make the drug more lipophilic to enhance loading into the carrier; but neither one has been developed successfully in the laboratory (86-88). Later, a complexation method between ionic polymers and drugs was proposed to obtain hybrid nanoparticles of lipid plus polymer as an option for delivering ionic anticancer drugs and chemosensitizers. Complexation occurs when counter-ions of polymers neutralize the ionic drug molecules. Compounds of this kind can then be incorporated into lipids for nanoparticle preparation. Results show a marked increase in encapsulation efficiency; for example, doxorubicin $\mathrm{HCl}$ increased from 20 to over $80 \%$ (89). Some anticancer drugs do not possess a charge. In these cases, the best strategy could be to prepare a more lipophilic derivative. An example was reported by Wang et al. (90), who found higher encapsulation efficiency $(>90 \%)$ of the lipophilic compound derivative than the native drug when incorporated into SLN. The major disadvantage is that the process requires tedious laboratory procedures to achieve chemical synthesis and evaluate safety, stability, and efficacy issues.

Recently, Kaushik et al. (91) proposed a system consisting of docetaxel (BCS class IV) conjugated with a biocompatible lipid (palmitic acid). They prepared conjugate-loaded SLN to enhance the solubility of this anticancer agent and improve pharmacokinetic parameters. Overall results indicate a decrease of $\mathrm{IC}_{50}$, an increased apoptotic index, lower affinity to Pgp-efflux (higher drug permeability), and improved pharmacokinetic and pharmacodynamic parameters for the conjugateloaded SLN than for free docetaxel (91). Another study demonstrated the benefits of modifying the superficial charge of nanoparticles. Cationic SLN loaded with $\mathrm{N}_{3}$-O-toluyl-fluorouracil (TFU) and stabilized with a positively-charged surfactant presented a 2-fold relative increase in bioavailability of TFU suspensions administered orally. Those researchers concluded that the enhanced gastrointestinal absorption was due to the cumulative effect of several factors: controlled drug release, increased dispersion in the gastrointestinal tract (GIT), and enhanced bioadhesion (between the positively-charged SLN and the negatively-charged mucus surface of the GIT) (92). The enhanced retention of positively charged nanoparticles observed in tumor cells is the result of its electrostatic attraction with the cancer cell surfaces, due to the 
presence of higher amount of negatively charged molecules such as sialic acid, chorionic gonadotropin, and anionic residues of RNA, in comparison of normal cells (93).

Another strategy for enhancing cancer treatments consists in controlling the extent and rate of drug release. When SLN were first introduced in the 1990s, observations showed that drug release followed a biphasic, non-uniform profile; a "burst effect" at the beginning usually followed by a slow, incomplete release. The main drawback of this fast release is that a large dose of the anticancer drug released all at once into the systemic circulation or near the administration site can be extremely hazardous (94). It is well-known that the "burst effect" is caused by the high crystallinity of lipids after producing the carriers, so preparing lipid carriers with less crystallinity will reduce this effect. This can be accomplished by mixing solid lipids or solid lipids plus oils to provide a structure with more inner spaces where larger quantities of certain oilsoluble drugs can be accommodated. One advantage of nanostructured lipid carriers is that they can carry greater payloads, but this could be an issue in cancer therapies. However, by the same token, if drug release includes an extended profile, then treatment at suboptimal levels could develop drug-resistant cells due to the expression of membrane-associated drug transporters (e.g. P-gp) $(95,96)$. Then, SLN formulation is required for a fast drug released but without a marked burst effect. In this respect, Wong et al. found that incorporating an ionic polymer into hybrid polymer lipid nanoparticles can favor the disintegration and dissociation of the drug-polymer complexes, with the latter becoming more hydrophilic. The presence of additional channels would allow faster release of the anticancer drug from the nanoparticles. To date, hydrochloride salts have been tested using this approach $(89,97)$.

In 2011, a study reported the preparation of modified chitosan SLN loaded with doxorubicin. The authors found a reduction from 22.30 to $6.76 \%$ of the burst effect and improved the drug's in vitro cellular uptake. Moreover, by modifying the amount and molecular weight of chitosan, a 72-h prolonged drug release was obtained (98). The authors of another experiment attempted to improve the oral bioavailability of salmon calcitonin included in modified SLN with two types of peptide ligand (CSKSSDYQC, IRQRRRR). Results showed that the modified SLN increased drug protection and aided in internalizing the protein into co-culture cells (human colon adenocarcinoma and goblet-like HT29-MTX cells), compared to SLN without the ligand. Moreover, protein bioavailability increased by about 2 -fold to show the benefits of using a peptidemodified SLN formulation (99).

In 2016, Soni et al. (100) formulated mannosylated SLN loaded with gemcitabine, a drug used to treat lung cancer, but has significant drawbacks: poor penetration into lung cancer cells and low blood residence time, and an inefficient pharmacokinetic/pharmacodynamic profile. Those authors reported highly satisfactory results, summarized as follows: in vivo targeted delivery in lung tumor cells, an improved targeted effect, and low toxicity to human erythrocytes. All these features made mannose-modified SLN an essential vehicle for delivering gemcitabine to target lung tumor cells with a high retention potential (100).

Two important reasons for modifying the surface of SLN with different ligands are to protect them from active surveillance by the immune system and from becoming "long-circulating" drug carriers, since they eventually evade the body's clearance mechanisms. As described previously, SLN may increase treatment efficacy by presenting higher specificity for the action site (reaching the target cells) and, consequently, decreasing cytotoxicity compared to conventional anticancer therapies (96). In the early 1990s, researchers coated SLN with polyethylene glycol (PEG) to render them more hydrophilic and increase circulation time $(78,101)$. Since then, this surface-modification strategy has been applied to prepare nanocarriers designed to attack cancer cells only while ignoring healthy cells by exploiting surface-antigen differences. This is feasible because the target antigen in cancer cells exerts a considerable impact on cellular function and does not mutate as the cancer cell populations spread (81).

Regarding PEG-SLN modification, Madan et al. (102) found higher plasma concentrations of noscapine after intravenous administration in mice of loaded SLN modified with PEG than the free drug and unmodified SLN. They concluded that RES could be avoided thanks to the presence of a "brush" formed by the PEG molecules on the nanoparticle surface. In terms of the increased specificity of modified SLN, Venishetty and cols (103) found a 44fold enhancement of the brain permeation coefficient of ketoconazole-loaded and folate-grafted docetaxel 
SLN compared to commercial docetaxel (Taxotere ${ }^{\circledR}$ ). This result was made possible by the receptormediated endocytosis exerted by the folic acid transporter, a ligand that binds to the over-expressed receptor on the surface of the cancer cell to improve SLN uptake into the tumor site, as in solid brain tumors. More recently, a similar result was obtained by Rajpoot et al. (104), whose folic acid-grafted SLN loaded with oxaliplatin had higher in vitro cytotoxicity on the HT-29 cell lines than on the nongrafted SLN or the drug solution. Those authors concluded that this is a promising approach for treating colorectal cancer. Another research group used anti-epithelial growth factor (EGF) to modify the surface of carmustine-loaded SLN, resulting in the inhibition of human brain malignant glioblastoma cells (105). In 2015, the serotonergic 1B receptor subtype antagonist (S1BRSA) was the ligand incorporated into carmustine-loaded SLN to deliver the drug with high specificity to the brain and inhibit glioblastoma multiforme (106). The goal of that study was achieved because growth inhibition of glioblastoma multiforme U87 MG cells was observed, attributable to SLN modified with S1BRSA to target the serotonergic 1B receptor subtype (S1BRS).

In 2017, Baek \& Cho (107) prepared Ncarboxymethyl chitosan-coated, curcumin-loaded SLN to delay the fast release of this anticancer agent in an acidic medium and so improve its stability and oral bioavailability. Their system proved to be successful because the burst release was suppressed in simulated gastric fluid, and sustained release was observed in simulated intestinal fluid. Moreover, the oral bioavailability of curcumin-loaded SLN was 9.5-fold higher than that of the control solution. In 2019, an exciting approach was developed by Xing et al. (108) to enhance the oral bioavailability of 2methoxyestradiol, an anti-tumor, anti-angiogenic, and anti-inflammatory estradiol metabolite characterized by low solubility and rapid elimination. The authors prepared modified SLN with PEG-PLC (polycarbonate) and embedded them in $\mathrm{pH}$-sensitive microparticles to decrease the release of methoxyestradiol in the stomach but increase it in the intestinal tract and prolong the retention and absorption time of the carriers. The aim was achieved because the multifunctional carriers significantly increased the oral bioavailability and prolonged duration of an effective serum concentration of 2- methoxyestradiol compared to the suspension after oral administration in rats.

Another technological strategy that has been employed recently to enhance the delivery of an anticancer drug is called co-delivery. This emerged because monotherapy treatment for some cancers was ineffective. In this case, SLN facilitated the administration of an anticancer drug co-delivered with therapeutic nucleic acids (109). Research has demonstrated enhanced anticancer efficacy using the co-delivery strategy compared to administering each drug or agent alone. Other advantages are that toxicity and some other side effects of treatment are reduced by combining agents in the same nanocarrier (110). A promising approach in this area includes RNA as a "companion" of an anticancer drug. Double-stranded RNA acts by inhibiting gene expression with complementary nucleotide sequences (111), while siRNA induces the silencing of coding genes of apoptosis, cell proliferation, and angiogenesis of tumor cells. In 2012, a study reported improved anticancer efficacy through the co-delivery of paclitaxel and human myeloid cell leukemia 1 (MCL1) contained in cationic SLN and tested in vitro and in vivo compared to each agent alone (109).

Another example involves paclitaxel and an anti-oncogene, microRNA-34, which is cancerspecific, encapsulated together in SLN. This formulation showed an important advance in eliminating tumor relapse in lung cancer treatment with better performance than that of single agentloaded formulations to inhibit B16F10-bearing tumor growth (110). An exciting modification of this strategy was developed by $\mathrm{Yu}$ et al. (112), who designed $\mathrm{pH}$-sensitive nanocarriers (SLN) to codelivery of paclitaxel and DNA. The ligand was hyaluronic acid, an acid-sensitive linker. The authors attributed the high efficiency achieved to this ligand due to improved cellular uptake and enhanced drug release into tumor cells. In 2014, other researchers developed $\mathrm{pH}$-sensitive SLN to target anticancer agents. In their work, doxorubicin was combined with docosahexaenoic acid, a long-chain polyunsaturated fatty acid (C22). Observations showed an increase in sensitivity to chemotherapy by tumor cells (79). Docosahexaenoic acid was also tested to produce doxorubicin-loaded SLN by Mussi and cols. (113). When the release was tested in a slightly acidic medium ( $\mathrm{pH}$ 5.0) compared to physiological $\mathrm{pH}$, drug release was higher. Furthermore, the cytotoxicity in this in vitro study 
revealed a higher level in the loaded SLN in the A549 cell line of human lung tumors; clearly, a promising result for cancer treatment. Research in this area shows that $\mathrm{pH}$-sensitive SLN can be obtained to target anticancer agents.

Gidwani \& Vyas (107) proposed a recent approach that involves preparing an inclusion compound of altretamine (a drug prescribed to treat ovarian cancer) and epichlorohydrin- $\beta$-cyclodextrin, and encapsulating this compound into SLN to enhance drug solubility and bioavailability. The authors elaborated a system with small particle size, bi-phasic drug release, a $\mathrm{C}_{\max } 2.47$ times higher than the pure drug, and an $\mathrm{AUC}_{\mathrm{t}} 2$ times higher than the pure suspension, indicating that the altretamine was absorbed better from the SLN. Improved oral bioavailability was achieved as a consequence of all these properties. Finally, resveratrol- and curcuminloaded SLN have been prepared due to reports that these two molecules have a synergistic effect on colorectal cancer, but there are two drawbacks: low water solubility and poor bioavailability (114). In this approach, researchers included a polymer (2hydroxypropyl $\beta$-cyclodextrin) to prevent the burst effect often observed in SLN. Results indicated that the in vitro release from SLN improved significantly compared to the pure drugs. Results for cytotoxicity in the in vitro assay showed anticancer activity of the carriers with or without the polymer.

\section{ENHANCED ANTIBIOTIC EFFECTIVENESS BY ORAL ADMINISTRATION OF SLN}

Antibiotic agents comprise some of the most widelyused therapeutic drugs in medical practice. The terms antibiotic, antimicrobial, and anti-infective encompass various pharmaceutical agents, including antibacterial, antifungal, antiviral, and antiparasitic drugs. The importance of antibiotics and how they have contributed to controlling infectious diseases is beyond debate; indeed, without their existence, human morbidity and mortality levels would be much higher than at present. The use of antibiotics, however, confronts some challenges, especially resistance to antibiotic therapy. Nanotechnologybased approaches have been proposed to prevent the development of resistance to antibiotics (115). According to Pelgrift and Freidman (116), approaches using nanoparticles to combat microbial resistance to antibiotics include:
1) Nanoparticles with multiple antimicrobial mechanisms; e.g. reactive oxygen species (ROS)-generator nanoparticles, more specifically RNOS (reactive nitrogen oxide species). Other examples are metal-based nanoparticles, including formulations with silver $(\mathrm{Ag})$, zinc $(\mathrm{Zn})$, copper $(\mathrm{Cu})$, titanium (Ti), magnesium $(\mathrm{Mg})$, and gold $(\mathrm{Au})$.

2) Inclusion of multiple antimicrobial drugs in one nanoparticle, Simultaneous resistance to various agents is unlikely, possibly because it would require multiple simultaneous gene mutations in the same bacterial cell.

3) Nanoparticles prevent the "decreased uptake/increased efflux of drugs" mechanism, reduce biofilm formation, and combat intracellular bacteria.

4) Nanoparticles that encapsulate antimicrobial agents for targeted drug delivery to administer higher doses at the infected site, thereby overcoming resistance with fewer adverse effects for patients.

SLN could impact the latter three points to improve the efficacy of antibiotics because they can (i) encapsulate multiple drugs (107); (ii) increase intracellular uptake of drugs (117), and (iii) be modified for active or passive targeting upon reaching the affected site to deliver the drug (79). SLN are also useful in reducing toxicity and improving the oral bioavailability of antibiotics. We know of several cases in which SLN have been used for this purpose. Chaudhari et al. (2015)(118) produced SLN of amphotericin B, a gold-standard, broad-spectrum antibiotic used in fungal and parasitic infections (e.g. visceral leishmaniasis) that, unfortunately, has significant side effects, including nephrotoxicity. In addition, oral delivery is reported to afford inadequate oral bioavailability. Those researchers found that amphotericin B included in NP possesses a relative bioavailability of 1.05 -fold, with a $\mathrm{C}_{\max }$ of $1,109.31 \pm 104.79 \mathrm{ng} / \mathrm{mL}$ after $24 \mathrm{~h}$ compared to a commercial formulation $\left(\right.$ Fungizone $\left.^{\circledR}\right)$, which reached a $\mathrm{C}_{\max }$ of $1,417.49 \pm$ $85.52 \mathrm{ng} / \mathrm{mL}$. In vivo biodistribution studies indicated deficient levels of amphotericin B in the kidneys when administrated in SLN, a finding corroborated by renal toxicity studies. Amphotericin $\mathrm{B}$ is a low water-soluble molecule that can selfaggregate due to its amphipathic character. It also presents a spontaneous self-aggregation pattern that 
results in the formation of monomers, water-soluble oligomers, and a water-insoluble super-aggregated form $(119,120)$. The aggregation state can modify its toxicity and pharmacokinetic characteristics. The oligomeric form is considered toxic due to its higher affinity to cholesterol that increases toxicity in mammalian cells in general, and in human cells specifically, since its presence in the kidney can produce nephrotoxicity (118). Encapsulation in SLN is a strategy that reduces the toxicity of amphotericin B, so this process both enhances oral bioavailability and provides a greater safety profile.

In another example of the use of amphotericin $\mathrm{B}$, Patel and Patravale (121) improved the $\mathrm{pH}$ stability of the antibiotic via SLN encapsulation that exhibited enhanced protection of the reagent at $\mathrm{pH}$ $1.2,4$, and 6.8. In vivo pharmacokinetic studies revealed an increase in the relative bioavailability of the drug in the SLN formulation compared to a solution. The $\mathrm{AUC}_{0-\infty}$ value for amphotericin $\mathrm{B}$ after oral administration in SLN was 2.15-fold higher than that of the drug in solution, while the percentage of relative bioavailability was 215.59 , a high value. Another example of an antibiotic encapsulated into SLN to reduce resistance was developed by Kumar et al. in 2016 (122). There, ceftriaxone was encapsulated into cholesterol-based SLN. Resistance to ceftriaxone has grown significantly due to misuse and overuse. Previously, Zhou et al. (123) had demonstrated how SLN increased the bioavailability of ofloxacin by 2.27 -fold and extended the mean residence time of the drug from 10.50 to 43.44 hours. Another successful case involves clarithromycin, a drug with low oral bioavailability and hepatotoxicity. However, when encapsulated in SLN, it showed higher $\mathrm{C}_{\max }$ (2.3-fold), $\mathrm{t}_{\max }$ (2-fold), mean residence time (MRT) (1.4-fold), and an almost 5-fold improvement in relative oral bioavailability compared to the drug in solution (124). In a complementary study, Öztürk et al. (125) determined the effect of a lipid matrix composition on the antimicrobial activity of clarithromycin loaded in SLN. In yet another case, enrofloxacin, an antibiotic with variable bioavailability due to its low aqueous solubility, has been formulated in SLN, but an encapsulation of enrofloxacin-loades SLN in enteric granules provided a relative bioavailability of $263.85 \%(126,127)$.

Tuberculosis is a major disease in which antimicrobial resistance has reached warning levels. According to the WHO, 480,000 people worldwide develop multi-drug resistance to tuberculosis each year. Tuberculosis is caused by the bacterium Tubercle bacilli that has the ability to remain viable in the air for a long time. The bacterium enters the human body by inhalation and begins its replication when alveolar macrophages capture it. Tuberculosis occurs mainly in the lungs but can also harbor in other central nervous system organs and can have a mortality rate of up to $50 \%$. Faced with this problem, nanoparticles can cross different barriers to reach cellular reservoirs of Mycobacterium tuberculosis. Nanoparticles can be inhaled and have a high degree of permeation in the lungs, allowing the release of biotechnological strategies. The facilitated transport of the nanoparticles could also decrease adverse effects and a greater expectation in the patient's quality of life (128).

However, the phenomenon of drug resistance is also beginning to complicate the fight against HIV and malaria (129). Because of the severity of these threats, several nanotechnological approaches have been developed. Various drug delivery systems microparticles, NPs, microsphere liposomes, and, of course, SLN- have been utilized as carriers of antituberculosis agents to target the site of infection or reduce dosing frequencies and improve patient compliance and outcomes. Table 1 presents some of the first- and second-line oral anti-tuberculosis drugs, including some types of nanoplatforms for drug delivery. SLN formulations provide some of the critical features of drug carriers that have been successfully employed in treating tuberculosis. Since 2005, Pandey et al. (136) have been exploring the potential of SLN-loaded anti-tuberculosis drugs (ATD) administered orally by testing in mice. In their work, three front-line ATD (rifampicin, isoniazid, pyrazinamide) were co-incorporated in SLN, as suggested by Pelgrift and Freidman, to combat microbial resistance to antibiotics (116). Preparation of SLN was by emulsion-solvent diffusion. The three drugs were incorporated into a lipid matrix of stearic acid. One of the challenges that needed to be overcome was that the drugs required different doses, but they all had to be present in the sample of SLN. Moreover, they have different entrapment efficiencies, so it was challenging to include them in the correct proportions. The most important finding of their work was that after a single oral administration of the SLN formulation, the drugs were detected in the plasma from $3 \mathrm{~h}$ up to $192 \mathrm{~h}$, while free drugs could not be detected in the plasma 
beyond $12 \mathrm{~h}$ of oral administration. In another case of ATD loaded into SLN, sustained drug levels were maintained in the organs (lung, liver, spleen) until day 10 , whereas free drugs were cleared from tissues in just 24-48 h. Because of the slow, sustained release of the drugs from the SLN, MRT increased several times compared to the free drugs. Rifampicin increased MRT from 6.2 to $91.3 \mathrm{~h}$, isoniazid from 5.5 to $97.6 \mathrm{~h}$, and pyrazinamide from 6.6 to $100.6 \mathrm{~h}$. Drugs incorporated into SLN appear to always exhibit longer MRT.

Table 1. First- and second-line oral antituberculosis drugs formulated in nanoparticles

\begin{tabular}{|c|c|c|}
\hline $\begin{array}{l}\text { Oral anti- } \\
\text { tuberculosis drugs }\end{array}$ & Nanoplatform & References \\
\hline \multirow{3}{*}{ Isoniazid } & $\begin{array}{l}\text { Polymeric } \\
\text { nanoparticles }\end{array}$ & $(130-132)$ \\
\hline & Inorganic nanoparticles & (133) \\
\hline & $\begin{array}{l}\text { Solid lipid } \\
\text { nanoparticles }\end{array}$ & (134) \\
\hline Pyrazinamide & $\begin{array}{l}\text { Polymeric } \\
\text { nanoparticles }\end{array}$ & (135) \\
\hline Ethambutol & $\begin{array}{l}\text { Polymeric } \\
\text { nanoparticles }\end{array}$ & $(136,137)$ \\
\hline \multirow{2}{*}{ Rifampicin } & $\begin{array}{l}\text { Polymeric } \\
\text { nanoparticles }\end{array}$ & $(138-141)$ \\
\hline & $\begin{array}{l}\text { Lipid-based } \\
\text { nanoparticles }\end{array}$ & (142) \\
\hline Streptomycin & $\begin{array}{l}\text { Solid lipid } \\
\text { nanoparticles }\end{array}$ & (143) \\
\hline p-aminosalicylic acid & $\begin{array}{l}\text { Inorganic } \\
\text { nanocomposite }\end{array}$ & (144) \\
\hline \multirow[t]{2}{*}{ Ethionamide } & $\begin{array}{l}\text { Polymeric } \\
\text { nanoparticles }\end{array}$ & $(145,146)$ \\
\hline & Inorganic nanoparticles & (147) \\
\hline Cycloserine & $\begin{array}{l}\text { Polymeric } \\
\text { nanoparticles }\end{array}$ & $(148,149)$ \\
\hline
\end{tabular}

The findings reviewed in this chapter demonstrate the advantages of SLN, especially their long-term stability and drug incorporation efficiency, which are enhanced compared to polymeric or liposomal formulations. Despite the advantages of the oral administration route, however, studies of the efficacy of multidrug encapsulation are still scarce, though SLN have been explored as an inhalable ATD carrier (150).

\section{CONCLUSIONS AND REMARKS}

To date, SLN represent formulations with low toxicity, controlled release application, drug targeting ability, and the capacity to include lipophilic or hydrophilic drugs. SLN are, therefore, an option for administering poorly-soluble molecules via the oral route since they act as enhancers of intestinal absorption and provide protection for the encapsulated drugs. A combination of specific longchain triglycerides with non-ionic emulsifiers has been shown to reduce the lipase-mediated degradation of SLN after oral administration. According to the main applications reported in the literature, the use of SLN to target drug delivery to the brain has increased in importance as alternative carriers for polymeric nanoparticles. Despite these advances, the proportional usage of this administration route remains very low due, primarily, to the challenge of maintaining integrity over the long pathway to the brain. For this purpose, a high degree of vectorization may be required that involves nuclear internalization. In addition, it is necessary to perform broad toxicity studies in different neural lines and to elucidate the mechanisms of internalization at the level of the brain.

The principal strategies developed to overcome the challenges of anticancer treatments that employ SLN include the following: encapsulation of watersoluble anticancer compounds; control of the drugrelease rate and degree of drug release; and preventing systemic clearance by the reticuloendothelial system. All these questions have been addressed with promising results. The challenges in using SLN with anticancer drugs include a limited number of clinical trials, the need to avoid leakage of highly water-soluble drugs during the encapsulation process, and special care in the release profile to decrease the potential development of drug-resistance because a slow interaction with malignant cells can promote and accelerate this process. Finally, SLN-based approaches have been proposed to prevent antibiotic resistance because these carriers can load multiple antimicrobial drugs, increase drug uptake, and decrease efflux from the bacteria, while simultaneously impeding biofilm formation. In addition, SLN can be targeted directly to the infection site, have the potential to reduce toxicity, and can significantly improve the oral 
bioavailability of antibiotics. For all these reasons, formulations based on SLN represent a viable alternative in terms of functionality and biocompatibility. Indeed, their applications will expand as novel therapeutic targets and drugs are developed. The main challenges that remain to be resolved include multiplying biocompatibility studies, further enhancing carrier performance, and performing subsequent clinical studies.

ACKNOWLEDGEMETS. The authors acknowledge the financial support from CONACYT A1-S-39237, CONACYT A1-S-15759, PAPIIT (DGAPA) IN222420 and IN223620 and PIAPI (FESC) 2040 and 2021.

\section{REFERENCES}

1. Shah MK, Khatri P, Vora N, Patel NK, Jain S, Lin S. Lipid nanocarriers: Preparation, characterization and absorption mechanism and applications to improve oral bioavailability of poorly water-soluble drugs. In: Biomedical Applications of Nanoparticles, Elsevier; 2019. p. 117-47. Doi: 10.1016/B978-0-12-816506-5.00003-6

2. Banerjee S, Pillai J. Solid lipid matrix mediated nanoarchitectonics for improved oral bioavailability of drugs. Expert Opin Drug Metab Toxicol, 2019;15(6):499-515. Doi: 10.1080/17425255.2019.1621289

3. Nair AB, Morsy MA, Shinu P, Kotta S, Chandrasekaran M, Abu Tahir M. Advances of non-iron metal nanoparticles in biomedicine. J Pharm Pharm Sci, 2021;24:4161.

4. Campos JR, Severino P, Santini A, Silva AM, Shegokar R, Souto SB, et al. Solid lipid nanoparticles (SLN). In: Nanopharmaceuticals, Elsevier; 2020. p. 1-15. Doi: 10.1016/B978-0-12-817778-5.00001-4

5. Urbán-Morlán Z, Ganem-Rondero A, Melgoza-Contreras LM, Escobar-Chávez JJ, Nava-Arzaluz MG, Quintanar-Guerrero D. Preparation and characterization of solid lipid nanoparticles containing cyclosporine by the emulsification-diffusion method. Int $\mathbf{J}$ Nanomedicine, 2010;5:611-20. Doi: 10.2147/IJN.S12125

6. Potta SG, Minemi S, Nukala RK, Peinado C, Lamprou DA, Urquhart A, et al. Development of solid lipid nanoparticles for enhanced solubility of poorly soluble drugs. J Biomed Nanotechnol, 2010;6(6):634-40.

7. $\mathrm{Hu}$ L, Tang X, Cui F. Solid lipid nanoparticles (SLNs) to improve oral bioavailability of poorly soluble drugs. J Pharm Pharmacol, 2010;56(12):1527-35.

8. Moradpour Z, Barghi L. Novel approaches for efficient delivery of tyrosine kinase inhibitors. J Pharm Pharm Sci, 2019;22:37-48.

9. Yang M, Gong W, Wang Y, Shan L, Li Y, Gao C. Bioavailability improvement strategies for poorly water-soluble drugs based on the supersaturation mechanism: An update. J Pharm Pharm Sci, 2016;19(2):208-25.

10. WHO. Cancer. 2012.

11. Mei L, Zhang Z, Zhao L, Huang L, Yang X-L, Tang J, et al. Pharmaceutical nanotechnology for oral delivery of anticancer drugs. Adv Drug Deliv Rev, 2013;65(6):880-90. Doi: 10.1016/j.addr.2012.11.005

12. Goldberg M, Gomez-Orellana I. Challenges for the oral delivery of macromolecules. Nat Rev Drug Discov, 2003;2(4):289-95. Doi: 10.1038/nrd 1067

13. Sant S, Tao SL, Fisher OZ, Xu Q, Peppas NA, Khademhosseini A. Microfabrication technologies for oral drug delivery. Adv Drug Deliv Rev, 2012;64(6):496-507. Doi: 10.1016/j.addr.2011.11.013

14. Zhang Z-H, Zhang Y, Zhou J-P, Lv H-X. Solid lipid nanoparticles modified with stearic acidoctaarginine for oral administration of insulin. Int J Nanomedicine, 2012;3333. Doi: 10.2147/IJN.S31711

15. Harde H, Das M, Jain S. Solid lipid nanoparticles: an oral bioavailability enhancer vehicle. Expert Opin Drug Deliv, 2011;8(11):1407-24.

Doi: 10.1517/17425247.2011.604311

16. Aungst BJ. Intestinal permeation enhancers. J Pharm Sci, 2000;89(4):429-42. Doi: $10.1002 /($ SICI) 1520 6017(200004)89:4<429::AIDJPS1>3.0.CO;2-J

17. Porter CJ., Charman WN. In vitro assessment of oral lipid based formulations. Adv Drug Deliv Rev, 2001;50:S127-47. Doi: 10.1016/S0169-409X(01)00182-X

18. Charman WN. Lipids, lipophilic drugs, and oral drug delivery-some emerging concepts. J 
Pharm Sci, 2000;89(8):967-78. Doi: 10.1002/1520-6017(200008)89:8<967::aidjps1>3.0.co;2-r

19. Mehnert W. Solid lipid nanoparticles Production, characterization and applications. Adv Drug Deliv Rev, 2001;47(2-3):165-96. Doi: $10.1016 / \mathrm{S} 0169-409 \mathrm{X}(01) 00105-3$

20. Muller RH, Keck CM. Challenges and solutions for the delivery of biotech drugs--a review of drug nanocrystal technology and lipid nanoparticles. J Biotechnol, 2004;113(13):151-70.

Doi: 10.1016/j.jbiotec.2004.06.007

21. Ravi PR, Vats R, Dalal V, Murthy AN. A hybrid design to optimize preparation of lopinavir loaded solid lipid nanoparticles and comparative pharmacokinetic evaluation with marketed lopinavir/ritonavir coformulation. J Pharm Pharmacol, 2014;66(7):912-26. Doi: 10.1111/jphp.12217

22. Jain S, Valvi PU, Swarnakar NK, Thanki K. Gelatin Coated Hybrid Lipid Nanoparticles for Oral Delivery of Amphotericin B. Mol Pharm, 2012;9(9):2542-53. Doi: 10.1021/mp300320d

23. Müller RH, Runge S, Ravelli V, Mehnert W, Thünemann AF, Souto EB. Oral bioavailability of cyclosporine: Solid lipid nanoparticles (SLN®) versus drug nanocrystals. Int J Pharm, 2006;317(1):82-9. Doi: 10.1016/j.ijpharm.2006.02.045

24. Zhang Z, Bu H, Gao Z, Huang Y, Gao F, Li Y. The characteristics and mechanism of simvastatin loaded lipid nanoparticles to increase oral bioavailability in rats. Int $\mathbf{J}$ Pharm, 2010;394(1-2):147-53. Doi: 10.1016/j.ijpharm.2010.04.039

25. Rizvi SZH, Shah FA, Khan N, Muhammad I, Ali KH, Ansari MM, et al. Simvastatin-loaded solid lipid nanoparticles for enhanced antihyperlipidemic activity in hyperlipidemia animal model. Int J Pharm, 2019;560:136-43. Doi: 10.1016/j.ijpharm.2019.02.002

26. Al-Heibshy FNS, Başaran E, Arslan R, Öztürk N, Erol K, Demirel M. Physicochemical characterization and pharmacokinetic evaluation of rosuvastatin calcium incorporated solid lipid nanoparticles. Int $\mathrm{J}$ Pharm, 2020;578:119106. Doi: 10.1016/j.ijpharm.2020.119106

27. Luo C-F, Yuan M, Chen M-S, Liu S-M, Zhu L, Huang B-Y, et al. Pharmacokinetics, tissue distribution and relative bioavailability of puerarin solid lipid nanoparticles following oral administration. Int J Pharm, 2011;410(12):138-44.

Doi: 10.1016/j.ijpharm.2011.02.064

28. Maleki Dizaj S, Rad AA, Safaei N, Salatin S, Ahmadian E, Sharifi S, et al. The Application of Nanomaterials in Cardiovascular Diseases: A Review on Drugs and Devices. J Pharm Pharm Sci, 2019;22:501-15.

29. Kakkar V, Singh S, Singla D, Kaur IP. Exploring solid lipid nanoparticles to enhance the oral bioavailability of curcumin. Mol Nutr Food Res, 2011;55(3):495-503. Doi: 10.1002/mnfr.201000310

30. Abuasal BS, Lucas C, Peyton B, Alayoubi A, Nazzal S, Sylvester PW, et al. Enhancement of Intestinal Permeability Utilizing Solid Lipid Nanoparticles Increases $\gamma$-Tocotrienol Oral Bioavailability. Lipids, 2012;47(5):461-9. Doi: 10.1007/s11745-012-3655-4

31. Chalikwar SS, Belgamwar VS, Talele VR, Surana SJ, Patil MU. Formulation and evaluation of Nimodipine-loaded solid lipid nanoparticles delivered via lymphatic transport system. Colloids Surfaces B Biointerfaces, 2012;97:109-16. Doi: 10.1016/j.colsurfb.2012.04.027

32. Zhang Z, Gao F, Bu H, Xiao J, Li Y. Solid lipid nanoparticles loading candesartan cilexetil enhance oral bioavailability: in vitro characteristics and absorption mechanism in rats. Nanomedicine Nanotechnology, Biol Med, 2012;8(5):740-7. Doi: 10.1016/j.nano.2011.08.016

33. Gambhire VM, Gambhire MS, Ranpise NS. Solid Lipid Nanoparticles of Dronedarone Hydrochloride for Oral Delivery: Optimization, In Vivo Pharmacokinetics and Uptake Studies. Pharm Nanotechnol, 2019;7(5):375-88. Doi: $10.2174 / 2211738507666190802140607$

34. Dwivedi P, Khatik R, Khandelwal K, Taneja I, Raju KSR, Wahajuddin, et al. Pharmacokinetics study of arteether loaded solid lipid nanoparticles: An improved oral bioavailability in rats. Int $\mathrm{J}$ Pharm, 2014;466(1-2):321-7. Doi: 10.1016/j.ijpharm.2014.03.036

35. Rehman MU, Khan MA, Khan WS, Shafique M, Khan M. Fabrication of Niclosamide 
loaded solid lipid nanoparticles: in vitro characterization and comparative in vivo evaluation. Artif Cells, Nanomedicine, Biotechnol, 2017;46(8):1-9. Doi: 10.1080/21691401.2017.1396996

36. Zhang X, Zhang T, Zhou X, Liu H, Sun H, Ma Z, et al. Enhancement of Oral Bioavailability of Tripterine Through Lipid Nanospheres: Preparation, Characterization, and Absorption Evaluation. J Pharm Sci, 2014;103(6):1711-9. Doi: $10.1002 / j p s .23967$

37. Ansari MJ, Anwer MK, Jamil S, Al-Shdefat R, Ali BE, Ahmad MM, et al. Enhanced oral bioavailability of insulin-loaded solid lipid nanoparticles: pharmacokinetic bioavailability of insulin-loaded solid lipid nanoparticles in diabetic rats. Drug Deliv, 2016;23(6):1972-9. Doi: 10.3109/10717544.2015.1039666

38. Gonçalves LMD, Maestrelli F, Di Cesare Mannelli L, Ghelardini C, Almeida AJ, Mura P. Development of solid lipid nanoparticles as carriers for improving oral bioavailability of glibenclamide. Eur J Pharm Biopharm, 2016;102:41-50. Doi: 10.1016/j.ejpb.2016.02.012

39. Cirri M, Mennini N, Maestrelli F, Mura P, Ghelardini C, Di Cesare Mannelli L. Development and in vivo evaluation of an innovative "Hydrochlorothiazide-in Cyclodextrins-in Solid Lipid Nanoparticles" formulation with sustained release and enhanced oral bioavailability for potential hypertension treatment in pediatrics. Int $\mathbf{J}$ Pharm, 2017;521(1-2):73-83. Doi: 10.1016/j.ijpharm.2017.02.022

40. Dudhipala N, Janga KY. Lipid nanoparticles of zaleplon for improved oral delivery by Box-Behnken design: optimization, in vitro and in vivo evaluation. Drug Dev Ind Pharm, 2017;43(7):1205-14.

Doi: 10.1080/03639045.2017.1304957

41. Aman RM, Abu Hashim II, Meshali MM. Novel chitosan-based solid-lipid nanoparticles to enhance the bio-residence of the miraculous phytochemical “Apocynin.” Eur J Pharm Sci, 2018;124:304-18. Doi: 10.1016/j.ejps.2018.09.001

42. Pandita D, Kumar S, Poonia N, Lather V. Solid lipid nanoparticles enhance oral bioavailability of resveratrol, a natural polyphenol. Food Res Int, 2014;62:1165-74.
Doi: 10.1016/j.foodres.2014.05.059

43. Kang X, Chen H, Li S, Jie L, Hu J, Wang X, et al. Magnesium lithospermate B loaded PEGylated solid lipid nanoparticles for improved oral bioavailability. Colloids Surfaces B Biointerfaces, 2018;161:597-605. Doi: 10.1016/j.colsurfb.2017.11.008

44. Pardeike J, Hommoss A, Müller RH. Lipid nanoparticles (SLN, NLC) in cosmetic and pharmaceutical dermal products. Int J Pharm, 2009;366(1-2):170-84. Doi: 10.1016/j.ijpharm.2008.10.003

45. Weyhers H, Ehlers S, Hahn H, Souto EB, Müller RH. Solid lipid nanoparticles (SLN)-effects of lipid composition on in vitro degradation and in vivo toxicity. Pharmazie, 2006;61(6):539-44.

46. Müller RH, Mäder K, Gohla S. Solid lipid nanoparticles (SLN) for controlled drug delivery - a review of the state of the art. Eur J Pharm Biopharm, 2000;50(1):161-77. Doi: 10.1016/s0939-6411(00)00087-4

47. Singh H, Jindal S, Singh M, Sharma G, Kaur IP. Nano-formulation of rifampicin with enhanced bioavailability: Development, characterization and in-vivo safety. Int $\mathbf{J}$ Pharm, 2015;485(1-2):138-51. Doi: 10.1016/j.ijpharm.2015.02.050

48. Mehnert W. Solid lipid nanoparticles Production, characterization and applications. Adv Drug Deliv Rev, 2001;47(2-3):165-96. Doi: 10.1016/S0169-409X(01)00105-3

49. Olbrich C, Müller R. Enzymatic degradation of SLN-effect of surfactant and surfactant mixtures. Int J Pharm, 1999;180(1):31-9. Doi: 10.1016/S0378-5173(98)00404-9

50. Olbrich C, Kayser O, Müller RH. Lipase degradation of Dynasan 114 and 116 solid lipid nanoparticles (SLN) - effect of surfactants, storage time and crystallinity. Int J Pharm, 2002;237(1-2):119-28. Doi: 10.1016/S0378-5173(02)00035-2

51. Olbrich C, Kayser O, Müller RH. Enzymatic degradation of Dynasan 114 SLN - Effect of surfactants and particle size. J Nanoparticle Res, 2002;4(1-2):121-9.

52. Testa B, Mayer JM. Classification, Localization, and Some Physiological Roles of Hydrolytic Enzymes. In: Testa B, Mayer JM, editors. Hydrolysis in Drug and Prodrug Metabolism, Zürich: Verlag Helvetica 
Chimica Acta; 2003. p. 11-46. Doi: 10.1002/9783906390444.ch2

53. Luo Y, Teng Z, Li Y, Wang Q. Solid lipid nanoparticles for oral drug delivery: Chitosan coating improves stability, controlled delivery, mucoadhesion and cellular uptake. Carbohydr Polym, 2015;122:221-9. Doi: 10.1016/j.carbpol.2014.12.084

54. Hu X, Fan W, Yu Z, Lu Y, Qi J, Zhang J, et al. Evidence does not support absorption of intact solid lipid nanoparticles via oral delivery. Nanoscale, 2016;8(13):7024-35. Doi: 10.1039/c5nr07474f

55. Zhang C, Gu C, Peng F, Liu W, Wan J, Xu H, et al. Preparation and Optimization of Triptolide-Loaded Solid Lipid Nanoparticles for Oral Delivery with Reduced Gastric Irritation. Molecules, 2013;18(11):13340-56. Doi: 10.3390/molecules181113340

56. Mohseni R, ArabSadeghabadi Z, Ziamajidi N, Abbasalipourkabir R, RezaeiFarimani A. Oral Administration of Resveratrol-Loaded Solid Lipid Nanoparticle Improves Insulin Resistance Through Targeting Expression of SNARE Proteins in Adipose and Muscle Tissue in Rats with Type 2 Diabetes. Nanoscale Res Lett, 2019;14(1):227. Doi: 10.1186/s11671-019-3042-7

57. El-Say KM, Hosny KM. Optimization of carvedilol solid lipid nanoparticles: An approach to control the release and enhance the oral bioavailability on rabbits. Ahmad A, editor. PLoS One, 2018;13(8):e0203405. Doi: 10.1371/journal.pone.0203405

58. Kakkar V, Muppu SK, Chopra K, Kaur IP. Curcumin loaded solid lipid nanoparticles: An efficient formulation approach for cerebral ischemic reperfusion injury in rats. Eur $\mathrm{J}$ Pharm Biopharm, 2013;85(3):339-45. Doi: 10.1016/j.ejpb.2013.02.005

59. Ganesan P, Ramalingam P, Karthivashan G, Ko YT, Choi D-K. Recent developments in solid lipid nanoparticle and surface-modified solid lipid nanoparticle delivery systems for oral delivery of phyto-bioactive compounds in various chronic diseases. Int $\mathbf{J}$ Nanomedicine, 2018;Volume 13:1569-83. Doi: 10.2147/IJN.S155593

60. Zhou Y, Zhang G, Rao Z, Yang Y, Zhou Q, Qin $\mathrm{H}$, et al. Increased brain uptake of venlafaxine loaded solid lipid nanoparticles by overcoming the efflux function and expression of P-gp. Arch Pharm Res, 2015;38(7):132535. Doi: 10.1007/s12272-014-0539-6

61. Leyva-Gómez G, González-Trujano ME, López-Ruiz E, Couraud P-O, Wekslerg B, Romero I, et al. Nanoparticle Formulation Improves the Anticonvulsant Effect of Clonazepam on the PentylenetetrazoleInduced Seizures: Behavior and Electroencephalogram. J Pharm Sci, 2014;103(8):2509-19. Doi: $10.1002 /$ jps. 24044

62. Müller CP, Reichel M, Mühle C, Rhein C, Gulbins E, Kornhuber J. Brain membrane lipids in major depression and anxiety disorders. Biochim Biophys Acta - Mol Cell Biol Lipids, 2015;1851(8):1052-65. Doi: 10.1016/j.bbalip.2014.12.014

63. Leyrolle Q, Layé S, Nadjar A. Direct and indirect effects of lipids on microglia function. Neurosci Lett, 2019;708:134348. Doi: 10.1016/j.neulet.2019.134348

64. Deng J, Yang Y, Luo L, Xiao Y, Luan T. Lipid analysis and lipidomics investigation by ambient mass spectrometry. TrAC Trends Anal Chem, 2020;128:115924. Doi: 10.1016/j.trac.2020.115924

65. Kiernan MC, Bostock H, Park SB, Kaji R, Krarup C, Krishnan A V., et al. Measurement of axonal excitability: Consensus guidelines. Clin Neurophysiol, 2020;131(1):308-23. Doi: 10.1016/j.clinph.2019.07.023

66. Lin K-L, Lin J-J, Wang H-S. Application of ketogenic diets for pediatric neurocritical care. Biomed J, 2020;43(3):218-25. Doi: 10.1016/j.bj.2020.02.002

67. Husari KS, Cervenka MC. The ketogenic diet all grown up-Ketogenic diet therapies for adults. Epilepsy Res, 2020;162(March):106319. Doi: 10.1016/j.eplepsyres.2020.106319

68. Arora N, Mehta TR. Role of the ketogenic diet in acute neurological diseases. Clin Neurol Neurosurg, 2020;192(January):105727. Doi: 10.1016/j.clineuro.2020.105727

69. Calderón N, Betancourt L, Hernández L, Rada P. A ketogenic diet modifies glutamate, gamma-aminobutyric acid and agmatine levels in the hippocampus of rats: A microdialysis study. Neurosci Lett, 2017;642:158-62. Doi: 10.1016/j.neulet.2017.02.014 
70. Kreuter J. Drug delivery to the central nervous system by polymeric nanoparticles: What do we know? Adv Drug Deliv Rev, 2014;71:214. Doi: 10.1016/j.addr.2013.08.008

71. Lalatsa A, Barbu E. Carbohydrate Nanoparticles for Brain Delivery. In: International Review of Neurobiology, 1st ed. Elsevier Inc.; 2016. p. 115-53. Doi: 10.1016/bs.irn.2016.05.004

72. Kawamura K, Yamasaki T, Konno F, Yui J, Hatori A, Yanamoto K, et al. Synthesis and in vivo evaluation of 18F-fluoroethyl GF120918 and XR9576 as positron emission tomography probes for assessing the function of drug efflux transporters. Bioorg Med Chem, 2011;19(2):861-70. Doi: 10.1016/j.bmc.2010.12.004

73. Mello JC de, Moraes VWR, Watashi CM, da Silva DC, Cavalcanti LP, Franco MKKD, et al. Enhancement of chlorpromazine antitumor activity by Pluronics F127/L81 nanostructured system against human multidrug resistant leukemia. Pharmacol Res, 2016;111:102-12. Doi: 10.1016/j.phrs.2016.05.032

74. Martins PP, Smyth HDC, Cui Z. Strategies to facilitate or block nose-to-brain drug delivery. Int J Pharm, 2019;570(August):118635. Doi: 10.1016/j.ijpharm.2019.118635

75. Bus T, Traeger A, Schubert US. The great escape: how cationic polyplexes overcome the endosomal barrier. J Mater Chem B, 2018;6(43):6904-18. Doi: 10.1039/C8TB00967H

76. Hernandez-Chan NG, Bannon MJ, OrozcoBarrios CE, Escobedo L, Zamudio S, De la Cruz F, et al. Neurotensin-polyplex-mediated brain-derived neurotrophic factor gene delivery into nigral dopamine neurons prevents nigrostriatal degeneration in a rat model of early Parkinson's disease. J Biomed Sci, 2015;22(1):59. Doi: 10.1186/s12929-0150166-7

77. Thanki K, Gangwal RP, Sangamwar AT, Jain S. Oral delivery of anticancer drugs: Challenges and opportunities. J Control Release, 2013;170(1):15-40. Doi: 10.1016/j.jconrel.2013.04.020

78. Geszke-Moritz M, Moritz M. Solid lipid nanoparticles as attractive drug vehicles: Composition, properties and therapeutic strategies. Mater Sci Eng C, 2016;68:982-94.
Doi: 10.1016/j.msec.2016.05.119

79. Rostami E, Kashanian S, Azandaryani AH, Faramarzi H, Dolatabadi JEN, Omidfar K. Drug targeting using solid lipid nanoparticles. Chem Phys Lipids, 2014;181:56-61. Doi: 10.1016/j.chemphyslip.2014.03.006

80. Eskandari Z, Bahadori F, Celik B, Onyuksel H. Targeted nanomedicines for cancer therapy, from basics to clinical trials. J Pharm Pharm Sci, 2020;23(1):132-57.

81. Wong H, Bendayan R, Rauth A, Li Y, Wu X. Chemotherapy with anticancer drugs encapsulated in solid lipid nanoparticles ir. Adv Drug Deliv Rev, 2007;59(6):491-504. Doi: 10.1016/j.addr.2007.04.008

82. Aji Alex MR, Chacko AJ, Jose S, Souto EB. Lopinavir loaded solid lipid nanoparticles (SLN) for intestinal lymphatic targeting. Eur J Pharm Sci, 2011;42(1-2):11-8. Doi: 10.1016/j.ejps.2010.10.002

83. Cavalli R, Caputo O, Gasco MR. Solid lipospheres of doxorubicin and idarubicin. Int J Pharm, 1993;89(1):R9-12. Doi: 10.1016/0378-5173(93)90313-5

84. Quintanar-Guerrero D, Allémann E, Fessi H, Doelker E. Applications of the ion-pair concept to hydrophilic substances with special emphasis on peptides. Pharm Res, 1997;14(2):119-27.

Doi: 10.1023/a:1012076022420

85. Olbrich C, Gessner A, Kayser O, Müller RH. Lipid-Drug-Conjugate (LDC) Nanoparticles as Novel Carrier System for the Hydrophilic Antitrypanosomal Drug Diminazenediaceturate. J Drug Target, 2002;10(5):387-96. Doi: 10.1080/1061186021000001832

86. Martins S, Sarmento B, Ferreira DC, Souto EB. Lipid-based colloidal carriers for peptide and protein delivery--liposomes versus lipid nanoparticles. Int $\mathrm{J}$ Nanomedicine, 2007;2(4):595-607.

87. Zhang X-G, Miao J, Dai Y-Q, Du Y-Z, Yuan H, Hu F-Q. Reversal activity of nanostructured lipid carriers loading cytotoxic drug in multidrug resistant cancer cells. Int J Pharm, 2008;361(1-2):239-44.

Doi: 10.1016/j.ijpharm.2008.06.002

88. Bondì ML, Fontana G, Carlisi B, Giammona G. Preparation and Characterization of Solid Lipid Nanoparticles Containing Cloricromene. 
Drug Deliv, 2003;10(4):245-50. Doi: 10.1080/drd_10_4_245

89. Wong HL, Bendayan R, Rauth AM, Wu XY. Development of solid lipid nanoparticles containing ionically complexed chemotherapeutic drugs and chemosensitizers. J Pharm Sci, 2004;93(8):1993-2008. Doi: 10.1002/jps.20100

90. Wang J-X, Sun X, Zhang Z-R. Enhanced brain targeting by synthesis of 3',5'-dioctanoyl-5fluoro-2'-deoxyuridine and incorporation into solid lipid nanoparticles. Eur J Pharm Biopharm, 2002;54(3):285-90. Doi: 10.1016/S0939-6411(02)00083-8

91. Kaushik L, Srivastava S, Panjeta A, Chaudhari D, Ghadi R, Kuche K, et al. Exploration of docetaxel palmitate and its solid lipid nanoparticles as a novel option for alleviating the rising concern of multi-drug resistance. Int J Pharm, 2020;578:119088. Doi: 10.1016/j.ijpharm.2020.119088

92. Liu D, Liu C, Zou W, Zhang N. Enhanced gastrointestinal absorption of N3-O-toluylfluorouracil by cationic solid lipid nanoparticles. J Nanoparticle Res, 2010;12(3):975-84. Doi: 10.1007/s11051009-9648-4

93. Saadat M, Zahednezhad F, Zakeri-Milani P, Heidari HR, Shahbazi-Mojarrad J, Valizadeh $\mathrm{H}$. Drug targeting strategies based on charge dependent uptake of nanoparticles into cancer cells. J Pharm Pharm Sci, 2019;22(1):191220.

94. zur Mühlen A, Schwarz C, Mehnert W. Solid lipid nanoparticles (SLN) for controlled drug delivery - Drug release and release mechanism. Eur J Pharm Biopharm, 1998;45(2):149-55. Doi: 10.1016/S09396411(97)00150-1

95. Hahn SM, Russo A, Cook JA, Mitchell JB. A multidrug-resistant breast cancer cell line induced by weekly exposure to doxorubicin. Int J Oncol, 1999;14(2):273-82. Doi: 10.3892/ijo.14.2.273

96. Campone M, Vavasseur F, Le Cabellec M, Meflah K, Vallette F, Oliver L. Induction of chemoresistance in HL-60 cells concomitantly causes a resistance to apoptosis and the synthesis of P-glycoprotein. Leukemia, 2001;15(9):1377-87.

10.1038/sj.leu.2402222
97. Wong HL, Rauth AM, Bendayan R, Manias JL, Ramaswamy M, Liu Z, et al. A New Polymer-Lipid Hybrid Nanoparticle System Increases Cytotoxicity of Doxorubicin Against Multidrug-Resistant Human Breast Cancer Cells. Pharm Res, 2006;23(7):1574-85. Doi: 10.1007/s11095-006-0282-X

98. Ying X-Y, Cui D, Yu L, Du Y-Z. Solid lipid nanoparticles modified with chitosan oligosaccharides for the controlled release of doxorubicin. Carbohydr Polym, 2011;84(4):1357-64. Doi: 10.1016/j.carbpol.2011.01.037

99. Fan T, Chen C, Guo H, Xu J, Zhang J, Zhu X, et al. Design and evaluation of solid lipid nanoparticles modified with peptide ligand for oral delivery of protein drugs. Eur J Pharm Biopharm, 2014;88(2):518-28. Doi: 10.1016/j.ejpb.2014.06.011

100. Soni N, Soni N, Pandey H, Maheshwari R, Kesharwani P, Tekade RK. Augmented delivery of gemcitabine in lung cancer cells exploring mannose anchored solid lipid nanoparticles. J Colloid Interface Sci, 2016;481:107-16. Doi: 10.1016/j.jcis.2016.07.020

101. Puri A, Loomis K, Smith B, Lee J-H, Yavlovich A, Heldman E, et al. Lipid-Based Nanoparticles as Pharmaceutical Drug Carriers: From Concepts to Clinic. Crit Rev Ther Drug Carr Syst, 2009;26(6):523-80. Doi: 10.1615/CritRevTherDrugCarrierSyst.v26.i6. 10

102. Madan J, Pandey RS, Jain V, Katare OP, Chandra R, Katyal A. Poly (ethylene)-glycol conjugated solid lipid nanoparticles of noscapine improve biological half-life, brain delivery and efficacy in glioblastoma cells. Nanomedicine Nanotechnology, Biol Med, 2013;9(4):492-503.

Doi: 10.1016/j.nano.2012.10.003

103. Venishetty VK, Komuravelli R, Kuncha M, Sistla R, Diwan P V. Increased brain uptake of docetaxel and ketoconazole loaded folategrafted solid lipid nanoparticles. Nanomedicine Nanotechnology, Biol Med, 2013;9(1):111-21.

Doi: 10.1016/j.nano.2012.03.003

104. Rajpoot K, Jain SK. Colorectal cancertargeted delivery of oxaliplatin via folic acidgrafted solid lipid nanoparticles: preparation, 
optimization, and in vitro evaluation. Artif Cells, Nanomedicine, Biotechnol, 2018;46(6):1236-47. Doi: $10.1080 / 21691401.2017 .1366338$

105. Kuo Y-C, Liang C-T. Inhibition of human brain malignant glioblastoma cells using carmustine-loaded catanionic solid lipid nanoparticles with surface anti-epithelial growth factor receptor. Biomaterials, 2011;32(12):3340-50. Doi: 10.1016/j.biomaterials.2011.01.048

106. Kuo Y-C, Wang C-C. Carmustine-loaded catanionic solid lipid nanoparticles with serotonergic $1 \mathrm{~B}$ receptor subtype antagonist for in vitro targeted delivery to inhibit brain cancer growth. J Taiwan Inst Chem Eng, 2015;46:1-14.

Doi: 10.1016/j.jtice.2014.08.035

107. Baek J-S, Cho C-W. Surface modification of solid lipid nanoparticles for oral delivery of curcumin: Improvement of bioavailability through enhanced cellular uptake, and lymphatic uptake. Eur J Pharm Biopharm, 2017;117:132-40. Doi: 10.1016/j.ejpb.2017.04.013

108. Xing Y, Liu X, Li X, Ding F, Zhang J, Guo X. PEG-PCL modification and intestinal sustained-release of solid lipid nanoparticles for improving oral bioavailability of 2methoxyestradiol. J Liposome Res, 2019;29(3):207-14. Doi: 10.1080/08982104.2018.1529792

109. Yu YH, Kim E, Park DE, Shim G, Lee S, Kim $\mathrm{YB}$, et al. Cationic solid lipid nanoparticles for co-delivery of paclitaxel and siRNA. Eur $\mathbf{J}$ Pharm Biopharm, 2012;80(2):268-73. Doi: 10.1016/j.ejpb.2011.11.002

110. Shi S, Han L, Deng L, Zhang Y, Shen H, Gong $\mathrm{T}$, et al. Dual drugs (microRNA-34a and paclitaxel)-loaded functional solid lipid nanoparticles for synergistic cancer cell suppression. J Control Release, 2014;194:228-37. Doi: 10.1016/j.jconrel.2014.09.005

111. Jin J, Bae KH, Yang H, Lee SJ, Kim H, Kim Y, et al. In Vivo Specific Delivery of c-Met siRNA to Glioblastoma Using Cationic Solid Lipid Nanoparticles. Bioconjug Chem, 2011;22(12):2568-72. Doi: $10.1021 / \mathrm{bc} 200406 \mathrm{n}$

112. Yu D, Li W, Zhang Y, Zhang B. Anti-tumor efficiency of paclitaxel and DNA when codelivered by $\mathrm{pH}$ responsive ligand modified nanocarriers for breast cancer treatment. Biomed Pharmacother, 2016;83:1428-35. Doi: 10.1016/j.biopha.2016.08.061

113. Mussi SV, Silva RC, Oliveira MC de, Lucci CM, Azevedo RB de, Ferreira LAM. New approach to improve encapsulation and antitumor activity of doxorubicin loaded in solid lipid nanoparticles. Eur J Pharm Sci, 2013;48(1-2):282-90. Doi: 10.1016/j.ejps.2012.10.025

114. Gumireddy A, Christman R, Kumari D, Tiwari A, North EJ, Chauhan H. Preparation, Characterization, and In vitro Evaluation of Curcumin- and Resveratrol-Loaded Solid Lipid Nanoparticles. AAPS PharmSciTech, 2019;20(4):145. Doi: 10.1208/s12249-0191349-4

115. Brooks BD, Brooks AE. Therapeutic strategies to combat antibiotic resistance. Adv Drug Deliv Rev, 2014;78:14-27. Doi: 10.1016/j.addr.2014.10.027

116. Pelgrift RY, Friedman AJ. Nanotechnology as a therapeutic tool to combat microbial resistance. Adv Drug Deliv Rev, 2013;65(1314):1803-15.

Doi: http://dx.doi.org/10.1016/j.addr.2013.07.011

117. Martins S, Costa-Lima S, Carneiro T, Cordeiro-da-Silva A, Souto EB, Ferreira DC. Solid lipid nanoparticles as intracellular drug transporters: An investigation of the uptake mechanism and pathway. Int $\mathbf{J}$ Pharm, 2012;430(1-2):216-27.

Doi: 10.1016/j.ijpharm.2012.03.032

118. Chaudhari MB, Desai PP, Patel PA, Patravale VB. Solid lipid nanoparticles of amphotericin B (AmbiOnp): in vitro and in vivo assessment towards safe and effective oral treatment module. Drug Deliv Transl Res, 2015; Doi: 10.1007/s13346-015-0267-6

119. Fanos V, Cataldi L. Amphotericin B-Induced Nephrotoxicity: A Review. J Chemother, 2000;12(6):463-70.

Doi: 10.1179/joc.2000.12.6.463

120. Torrado JJ, Espada R, Ballesteros MP, Torrado-Santiago S. Amphotericin B Formulations and Drug Targeting. J Pharm Sci, 2008;97(7):2405-25. Doi: 10.1002/jps.21179

121. Patel PA, Patravale VB. AmbiOnp: Solid lipid 
nanoparticles of amphotericin B for oral administration. J Biomed Nanotechnol, 2011;7(5):632-9.

122. Kumar S, Bhanjana G, Kumar A, Taneja K, Dilbaghi N, Kim KH. Synthesis and optimization of ceftriaxone-loaded solid lipid nanocarriers. Chem Phys Lipids, 2016;200:126-32. Doi: 10.1016/j.chemphyslip.2016.09.002

123. Zhou W, Shuyu Xie, Luyan Zhu, Zhao Dong, Wang Y, Xiaofang Wang. Preparation and evaluation of ofloxacin-loaded palmitic acid solid lipid nanoparticles. Int J Nanomedicine, 2011;547.

124. Sharma M, Gupta N, Gupta S. Implications of designing clarithromycin loaded solid lipid nanoparticles on their pharmacokinetics, antibacterial activity and safety. RSC Adv, 2016;6(80):76621-31.

Doi: 10.1039/C6RA12841F

125. Öztürk AA, Aygül A, Şenel B. Influence of glyceryl behenate, tripalmitin and stearic acid on the properties of clarithromycin incorporated solid lipid nanoparticles (SLNs): Formulation, characterization, antibacterial activity and cytotoxicity. J Drug Deliv Sci Technol, 2019;54(May):101240. Doi: 10.1016/j.jddst.2019.101240

126. Xie S, Yang F, Tao Y, Chen D, Qu W, Huang $\mathrm{L}$, et al. Enhanced intracellular delivery and antibacterial efficacy of enrofloxacin-loaded docosanoic acid solid lipid nanoparticles against intracellular Salmonella. Sci Rep, 2017;7(1):41104. Doi: 10.1038/srep41104

127. Li C, Zhou K, Chen D, Xu W, Tao Y, Pan Y, et al. Solid lipid nanoparticles with enteric coating for improving stability, palatability, and oral bioavailability of enrofloxacin. Int $\mathbf{J}$ Nanomedicine, 2019;14:1619-31. Doi: 10.2147/IJN.S183479

128. Ranjita S, Shaal A, Khalil M. Present Status Tuberculosis of Nanoparticle for Treatment of. J Pharm Pharm Sci, 2011;14(1):100-16.

129. World Health Organization. Antimicrobial resistance [Internet]. 2020.

130. Pourshahab PS, Gilani K, Moazeni E, Eslahi H, Fazeli MR, Jamalifar H. Preparation and characterization of spray dried inhalable powders containing chitosan nanoparticles for pulmonary delivery of isoniazid. $\mathbf{J}$ Microencapsul, 2011;28(7):605-13. Doi:

\subsection{9/02652048.2011.599437}

131. Hwang AA, Lee B-Y, Clemens DL, Dillon BJ, Zink JI, Horwitz MA. pH-Responsive Isoniazid-Loaded Nanoparticles Markedly Improve Tuberculosis Treatment in Mice. Small, 2015;11(38):5066-78. Doi: 10.1002/smll.201500937

132. Moin A, Raizaday A, Hussain T, Nagshubha B. Development and Optimization of Dual Drugs (Isoniazid and Moxiflox-acin) Loaded Functional PLGA Nanoparticles for the Synergistic Treatment of Tuberculosis. Curr Drug Deliv, 2016;13(7):1034-52. Doi: 10.2174/1567201813666160502124811

133. Sedlák M, Bhosale DS, Beneš L, Palarčík J, Kalendová A, Královec K, et al. Synthesis and characterization of a $\mathrm{pH}$-sensitive conjugate of isoniazid with $\mathrm{Fe} 3 \mathrm{O} 4 @ \mathrm{SiO} 2$ magnetic nanoparticles. Bioorg Med Chem Lett, 2013;23(16):4692-5. Doi: 10.1016/j.bmcl.2013.05.103

134. Bhandari R, Kaur IP. Pharmacokinetics, tissue distribution and relative bioavailability of isoniazid-solid lipid nanoparticles. Int $\mathbf{J}$ Pharm, 2013;441(1-2):202-12. Doi: 10.1016/j.ijpharm.2012.11.042

135. Varma JNR, Kumar TS, Prasanthi B, Ratna JV. Formulation and Characterization of Pyrazinamide Polymeric Nanoparticles for Pulmonary Tuberculosis: Efficiency for Alveolar Macrophage Targeting. Indian $\mathbf{J}$ Pharm Sci, 77(3):258-66. Doi: 10.4103/0250474x.159602

136. Pandey R, Sharma S, Khuller GK. Oral solid lipid nanoparticle-based antitubercular chemotherapy. Tuberculosis, 2005;85(56):415-20.

Doi: http://dx.doi.org/10.1016/j.tube.2005.08.009

137. Sharma A, Pandey R, Sharma S, Khuller GK. Chemotherapeutic efficacy of poly (dl-lactideco-glycolide) nanoparticle encapsulated antitubercular drugs at sub-therapeutic dose against experimental tuberculosis. Int $\mathbf{J}$ Antimicrob Agents, 2004;24(6):599-604. Doi: 10.1016/j.ijantimicag.2004.07.010

138. Sung JC, Padilla DJ, Garcia-Contreras L, VerBerkmoes JL, Durbin D, Peloquin CA, et al. Formulation and Pharmacokinetics of SelfAssembled Rifampicin Nanoparticle Systems for Pulmonary Delivery. Pharm Res, 2009;26(8):1847-55. Doi: 10.1007/s11095- 
009-9894-2

139. Ohashi K, Kabasawa T, Ozeki T, Okada H. One-step preparation of rifampicin/poly(lactic-co-glycolic acid) nanoparticle-containing mannitol microspheres using a four-fluid nozzle spray drier for inhalation therapy of tuberculosis. J Control Release, 2009;135(1):19-24. Doi: 10.1016/j.jconrel.2008.11.027

140. Patel BK, Parikh RH, Aboti PS. Development of oral sustained release rifampicin loaded chitosan nanoparticles by design of experiment. J Drug Deliv, 2013;2013:370938. Doi: 10.1155/2013/370938

141. Vibe CB, Fenaroli F, Pires D, Wilson SR, Bogoeva V, Kalluru R, et al. Thioridazine in PLGA nanoparticles reduces toxicity and improves rifampicin therapy against mycobacterial infection in zebrafish. Nanotoxicology, 2016;10(6):680-8. Doi: 10.3109/17435390.2015.1107146

142. Sanzhakov MA, Prozorovskyi VN, Ipatova OM, Tikhonova EG, Medvedeva NV, Torkhovskaya TI. Drug delivery system on the base of phospholipid nanoparticles for rifampicin. Biomeditsinskaya Khimiya, 2013;59(5):585-90.

Doi: 10.18097/pbmc20135905585

143. Kumar M, Kakkar V, Mishra AK, Chuttani K, Kaur IP. Intranasal delivery of streptomycin sulfate (STRS) loaded solid lipid nanoparticles to brain and blood. Int J Pharm, 2014;461(12):223-33.

Doi: 10.1016/j.ijpharm.2013.11.038

144. Saifullah B, Hussein MZ, Hussein-Al-Ali SH, Arulselvan P, Fakurazi S. Sustained release formulation of an anti-tuberculosis drug based on para-amino salicylic acid-zinc layered hydroxide nanocomposite. Chem Cent J, 2013;7(1):72. Doi: 10.1186/1752-153X-7-72

145. Kumar G, Sharma S, Shafiq N, Pandhi P, Khuller GK, Malhotra S. Pharmacokinetics and tissue distribution studies of orally administered nanoparticles encapsulated ethionamide used as potential drug delivery system in management of multi-drug resistant tuberculosis. Drug Deliv, 2011;18(1):65-73. Doi: 10.3109/10717544.2010.509367

146. Kumar G, Malhotra S, Shafiq N, Pandhi P, Khuller GK, Sharma S. In vitro physicochemical characterization and short term in vivo tolerability study of ethionamide loaded PLGA nanoparticles: potentially effective agent for multidrug resistant tuberculosis. J Microencapsul, 2011;28(8):717-28.

Doi: 10.3109/02652048.2011.615948

147. Vale N, Correia A, Silva S, Figueiredo P, Mäkilä E, Salonen J, et al. Preparation and biological evaluation of ethionamidemesoporous silicon nanoparticles against Mycobacterium tuberculosis. Bioorg Med Chem Lett, 2017;27(3):403-5. Doi: 10.1016/j.bmcl.2016.12.060

148. Shaji J, Shaikh M. Nebulizable Cycloserine Loaded PLGA Nanoparticles: Formulation Design, in vitro Evaluation and Stability Studies. Curr Nanomedicine, 2016;6(3):21939.

Doi:

$10.2174 / 2468187306666160711170333$

149. Musumeci T, Ventura CA, Carbone C, Pignatello R, Puglisi G. Effects of external phase on D-cycloserine loaded W/O nanocapsules prepared by the interfacial polymerization method. Eur J Med Chem, 2011;46(7):2828-34.

Doi: 10.1016/j.ejmech.2011.04.003

150. Pandey R, Khuller GK. Solid lipid particlebased inhalable sustained drug delivery system against experimental tuberculosis. Tuberculosis, 2005;85(4):227-34. Doi: 10.1016/j.tube.2004.11.003 